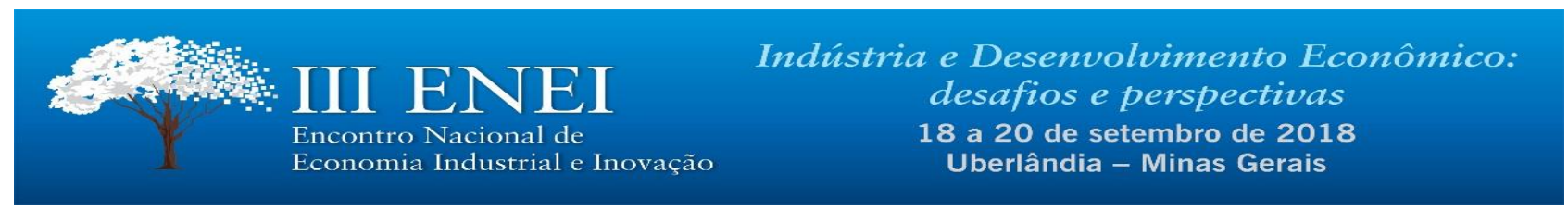

\title{
SURVEYS DE INOVAÇÃO DO BRASIL: UMA ANÁLISE COMPARATIVA COM SURVEYS INTERNACIONAIS
}

\author{
Thales de Oliveira Costa Viegas ${ }^{1}$ \\ Germano Mendes de Paula ${ }^{2}$ \\ Lídia Silveira Arantes ${ }^{3}$
}

\section{RESUMO}

O objetivo precípuo deste trabalho é apresentar as evidências brasileiras das principais surveys de inovação (Sondagem da Inovação e Pintec). O fito secundário é realizar uma comparação de aspectos metodológicos de surveys realizadas em regiões do mundo selecionadas. Adicionalmente, pretende-se comparar os resultados da Pintec com aqueles verificados em outros países. As surveys brasileiras seguem os padrões internacionais de coleta e tratamento de dados sobre inovação e pesquisa e desenvolvimento (P\&D) conforme o "Manual de Oslo". Isso promove certo grau de compatibilidade metodológica entre as pesquisas nacionais e as surveys internacionais. Contudo, ainda há desafios metodológicos significativos para serem superados pelo conjunto das surveys e por alguns instrumentos, em particular, dos países que as aplicam. Tal situação impõe dificuldades aos esforços de comparação internacional dos resultados dessas pesquisas. $\mathrm{O}$ foco geral das innovation surveys é monitorar o processo de inovação para permitir um melhor entendimento deste processo e os efeitos da inovação sobre a economia e, particularmente, para o desenvolvimento de políticas públicas. A Europa foi pioneira nas innovation surveys e desenvolveu uma metodologia comum que serviu de base para outras iniciativas de pesquisa ao redor do mundo. No Brasil os indicadores encontrados na Pintec são sistematicamente inferiores aos da Sondagem da inovação, pois há um viés de seleção na amostra desta última, que é composta apenas por grandes empresas. É um fato estilizado que as firmas maiores tendem a inovar mais em todo o mundo. O cotejo intertemporal dos indicadores da Sondagem mostra uma tendência de queda, enquanto os resultados da Pintec estão mais próximos de uma relativa estabilidade em seu conjunto. Todavia, cumpre notar que a periodicidade delas é distinta, uma vez que a Sondagem é trimestral e a Pintec é trienal. Já a comparação internacional evidencia que o Brasil apresenta, majoritariamente, indicadores consideravelmente piores do que aqueles verificados entre os países líderes europeus, tanto no que se refere aos esforços de inovação quanto no que tange aos seus resultados. Conclui-se que há muito o que se avançar em termos de realização de inovações relevantes no Brasil, bem como no que tange à qualidade e comparabilidade dos instrumentos empregados nas surveys ao redor do mundo, aprimorando a sua aplicabilidade nas políticas públicas dos países.

Palavras-Chave: Survey de Inovação; Desempenho Inovativo; Produto; Processo.

Área Temática: Indicadores de Ciência, Tecnologia, Inovação (5.8)

JEL: O39

\footnotetext{
${ }^{1}$ Professor Adjunto do Departamento de Ciências Econômicas da Universidade Federal de Santa Maria

${ }^{2}$ Professor Titular do Instituto de Economia e Relações Internacionais da Universidade Federal de Uberlândia

${ }^{3}$ Mestranda em Economia e Desenvolvimento da Universidade Federal de Santa Maria
} 


\begin{abstract}
The main objective of this paper is to present the Brazilian evidence of the main innovation surveys (Sondagem da Inovação and Pintec). The secondary aim is to make a comparison of methodological aspects of surveys carried out in selected regions of the world. Additionally, it is intended to compare the results of Pintec with those verified in other countries. The Brazilian surveys follow the international standards for collecting and processing data on innovation and Research \& Development (R\&D) according to the "Oslo Manual". This promotes a degree of methodological compatibility between national surveys and international surveys. However, there are still significant methodological challenges to be overcome by the set of surveys and by some instruments, in particular, by the countries that apply them. This situation presents difficulties for the international comparison of the results of these surveys. The overall focus of innovation surveys is to monitor the innovation process to allow a better understanding of this process and the effects of innovation on the economy and particularly on the policymaking. Europe pioneered innovation surveys and developed a common methodology that served as the basis for other research initiatives around the world. In Brazil the indicators found in Pintec are systematically inferior to those of the Sondagem da Inovação, since there is a selection bias in the sample of the latter, which is composed only by large companies. It is a stylized fact that larger firms tend to innovate more around the world. The intertemporal comparison of the Survey indicators shows a downward trend, while the results of Pintec are closer to relative stability in global terms. The international comparison, on the other hand, shows that Brazil has, in the main, considerably worse indicators than those found among the leading European countries. It is concluded that there is much to be done in terms of the achievement of relevant innovations in Brazil, as well as in the quality and comparability of the instruments used in the surveys around the world, improving their applicability in the public policies of the countries.
\end{abstract}

\title{
INTRODUÇÃO
}

O objetivo principal deste trabalho é apresentar as evidências brasileiras oriundas das surveys de inovação elaboradas no país, a saber: a sondagem de inovação da Agência Brasileira de Desenvolvimento Industrial (ABDI) e a Pintec realizada pelo Instituto Brasileiro de Geografia e Estatística (IBGE). O fito secundário é realizar uma comparação das experiências das surveys no mundo com as do Brasil, bem como das metodologias e resultados locais com aqueles verificados em outros países. A Sondagem de Inovação segue os padrões internacionais de coleta e tratamento de dados sobre pesquisa e desenvolvimento (P\&D) conforme o "Manual de Oslo". O cotejo entre diferentes experiências de survey passa pela identificação de traços conceituais e metodológicos em comum, bem como por indicadores compatíveis e passíveis de comparação. Isto possibilita compatibilidade metodológica da Pesquisa de Inovação Tecnológica (Pintec) com pesquisas internacionais, tais como o Community Innovation Survey (CIS), realizadas em países da União Europeia. Também serão cotejados aspectos metodológicos das surveys nacionais com aquelas executadas em países asiáticos, africanos e do continente americano.

As atividades de ciência e tecnologia (C\&T) vêm adquirindo crescente importância nas políticas públicas voltadas para o fomento industrial. Nesse contexto, a Sondagem de Inovação, elaborada para a ABDI, cumpre um papel de fornecer subsídios para a elaboração e o monitoramento das políticas industriais, uma vez que apresenta dados trimestrais acerca da evolução da inovação tecnológica na indústria e suas perspectivas. A Sondagem gera indicadores conjunturais (trimestrais) que permitem o monitoramento contínuo dos esforços inovativos das grandes empresas no Brasil, de modo a servir de instrumento para a gestão das políticas públicas de inovação e de tecnologia do país.

O IBGE, por seu turno, realizada a cada triênio a Pesquisa de Inovação Tecnológica (Pintec), que é uma pesquisa de corte transversal. Publicou, em 2002, a sua primeira edição, denominada Pintec 2000, cobrindo o período de 1998 a 2000. Ao longo de suas diferentes edições, o instrumento foi aperfeiçoado em diferentes dimensões, a exemplo dos seguintes aspectos: i) ampliação da amostra; ii) regionalização dos resultados; iii) inclusão de novos setores como o de serviços; iv) divulgação de estatísticas mais desagregadas. Entre as atividades investigadas estão as indústrias extrativas e de transformação, bem como os setores de eletricidade e gás, somados a um conjunto de serviços selecionados. Não houve mudança significativa entre 
a Pintec 2011 e a edição 2014, o que permite o pleno cotejo entre elas. Em suma, a Pintec objetiva construir indicadores setoriais de inovação (em níveis nacional e regional), compatíveis com as recomendações internacionais, em termos conceituais e metodológicos, direcionadas às surveys de inovação. A Pintec gera informações sobre os seguintes elementos: i) gastos com inovação; ii) fontes de financiamento destes dispêndios; iii) efeito das inovações no desempenho das empresas; iv) fontes de informações utilizadas; v) arranjos cooperativos; vi) papel dos incentivos governamentais; vii) obstáculos às atividades de inovação; viii) inovações organizacionais e; ix) uso de biotecnologia e nanotecnologia (IBGE, 2016).

Cumpre notar, desde logo, que a baixa motivação para realizar esforços tecnológicos, por parte das empresas instaladas no Brasil, está associado às características da indústria local, na qual predominam setores de menor densidade tecnológica, bem como grande presença de multinacionais em setores de maior intensidade tecnológica. Estas últimas, historicamente, realizaram fora do país a maior parte das suas atividades de $\mathrm{P} \& \mathrm{D}$, concentrando seus esforços locais nas iniciativas e adaptação de produtos e processos ao mercado nacional. Nessas condições, o setor manufatureiro brasileiro produz pouca tecnologia quando comparado à indústria mundial, especialmente dos países desenvolvidos.

\section{SURVEYS DE INOVAÇÃO: CARACTERÍSTICAS E LIMITAÇÕES}

Survey corresponde a uma pesquisa de campo com o intuito de obter dados primários. Trata-se de um método amplamente utilizado, mediante questionário ou outras técnicas estruturadas, para se coletar observações sobre o objeto ou o tema pesquisado. A realização de uma survey fornece subsídios para que o pesquisador realize análises com maior profundidade sobre os conteúdos e fenômenos estudados. Esse tipo de pesquisa é caracterizado pela busca por dados sobre ações, características, ou percepções (opniões) de determinados indivíduos (ou grupos). É possível que a coleta de dados seja realizada junto à toda a população que compõe o público alvo da pesquisa. No entanto, ela também pode se circunscrever a uma amostra deste coletivo, o que envolve uma técnica de amostragem e desafios correlatos à sua capacidade de representar a população alvo da pesquisa (FREITAS et al, 2000; VAUS, 2002; FOWLER, 2013).

O objetivo geral das surveys de inovação, particularmente, é monitorar o processo inovativo para permitir um melhor entendimento deste fenômeno e dos seus efeitos sobre a economia, em especial, para subsidiar o desenvolvimento de políticas industriais e de inovação de um país (FOYN, 2006). Uma survey de inovação (do inglês, innovation survey), em específico, tem o intuito de captar informações sobre o comportamento inovativo das empresas, ou seja, sobre as atividades que geram inovações organizacionais e tecnológicas (de produto e de processo). Estes dados correspondem a variáveis de resultado (output) das atividades inovativas, que podem resultar de esforços de inovação (inputs ou insumos), manifestos, por exemplo, em gastos com Pesquisa e Desenvolvimento (P\&D) de novas tecnologias. A publicação do Manual Frascati (1962) forneceu uma estrutura conceitual para a mensuração de P\&D como indicador de inovação. A sua construção foi internacionamente coletiva, realizada no âmbito de uma organização multilateral como é a Organização para a Cooperação e Desenvolvimento Econômico (OCDE). A consistência internacional das estatísticas permitiu a comparabilidade das estatísticas de diversos países (GODIN, 2008; STEWARD, 2008). A última edição do Manual Frascati foi divulgada em 2015.

As surveys de P\&D foram precursoras das surveys de inovação, as quais incorporam os indicadores de resultado do processo inovativo. Neste particular, a publicação, em 1992, do Manual de Oslo forneceu o arcabouço conceitual e as diretrizes para estas últimas. Na medida em que também foi confeccionado, coletivamente, no âmbito da OCDE, este documento constituiu um padrão internacional para que as surveys de inovação de diversos países pudessem ser comparadas. O conteúdo do Manual de Oslo foi sendo aprimorado a cada uma de suas três edições (1992, 1997 e 2005). Ao longo do tempo ele foi se afastando do modelo linear de inovação e se aproximando daquele que é denominado elo de cadeia. No primeiro deles a inovação é compreendida como um processo que ocorre em etapas sequenciais, o qual se inicia pela pesquisa básica (etapa que gera conhecimentos elementares), passa pela segunda etapa, consubstanciada na pesquisa aplicada e se completa com as etapas de desenvolvimento, produção e difusão da inovação (GODIN, 2005).

Mesmo assim, segundo Salazar e Holbrook (2004), o Manual de Oslo confere significativa importância para dados de P\&D (insumos), enquanto observa apenas marginalmente os processos reais, as dinâmicas, 
os relacionamentos e interações (entre firmas) que afetam a inovação. Há que se considerar que a atividade inovativa mudou e tem sido realizada cada vez mais por intermédio da cooperação entre empresas, o que representa um desafio para as surveys de inovação, as quais têm a firma como unidade de análise, mesmo que a inovação seja um resultado cada vez mais coletivo. Geralmente, uma firma não inova sozinha. Nesse contexto, os autores contestam a categorização binária entre inovadores e não inovadores, bem como questionam a eficiência destes instrumentos em fornecer as melhores informações possíveis sobre a propensão e a capacidade das firmas de inovar. Eles advogam pelo entendimento da inovação como uma atividade, antes de ser um resultado propriamente dito.

Ainda de acordo com Salazar e Holbrook (2004), com o passar do tempo as atividades de inovação se tornaram mais cooperativas, globalizadas e complexas, o que requer maior rigor em mensuração e análise, assim como a coleta de dados relativa a distritos industrias e cadeias de valor, por exemplo. Neste sentido, Tomlinson (2000) argumenta que não faz mais sentido considerar que a fonte da inovação é uma única empresa na moderna economia global, mas sim de inovações que surgem por meio de redes complexas de firmas e instituições, as quais contribuem de alguma forma para a produção de novas inovações. $\mathrm{O}$ autor cita o exemplo da indústria de tecnologia da informação e comunicação, na qual as inovações de um único produto se desenvolvem por meio de extensas colaborações entre os setores de hardware, software e telecomunicações.

Essas surveys baseadas no Manual de Oslo fornecem indicadores para o benchmarking, o monitoramento e a avaliação comparativa do desempenho inovativo dos países (ARUNDEL, 2007). No entanto, estes instrumentos têm de lidar com a natureza bastante heterogênea do fenômeno inovação (ARCHIBUGI e PIANTA, 1996). Uma taxa de inovação em determinado nível não revela qual a importância ou a intensidade das inovações realizadas. Ademais, a despeito dos esforços de padronização, podem haver diferenças nos métodos de amostragem, no formato ou configuração do questionário, ou mesmo nos procedimentos de coleta de dados. Outros fatores que podem afetar os resultados são as diferenças culturais, que impactam na interpretação da inovação, ou simples problemas de tradução, que podem deturpar as questões e os conceitos padronizados (O'BRIEN, 2013). Contudo, há que se registrar que esses desafios são inerentes a qualquer pesquisa de campo.

Compartilhando de preocupação semelhante com a qualidade das informações coletadas pelas pesquisas sobre inovação, Romeiro et al (2012) alertam para a ocorrência de viés da informação em levantamentos de dados, decorrente da compreensão imprecisa do conceito de inovação por parte dos respondentes, o que requer mecanismos de minimização desse tipo de erro. Adicionalmente, segundo Step (2000), as diferenças entre taxas de resposta tiveram algum impacto nas primeiras edições da CIS, uma vez que em alguns países as amostras apresentam viés na direção das firmas que inovam, devido ao baixo índice de resposta das firmas que não inovam. A consequência é que a taxa de inovação destes países é inflada de forma espúria.

Ademais, diferentes países apresentam distintos padrões de renda, educacionais, de força de trabalho, infraestrutura, institucionais e de qualidade da regulação. O desafio nesse contexto é estabelecer arcabouços metodológicos e procedimentais comparáveis entre surveys de diferentes países. Cabe salientar, que importantes progressos têm sido logrados nessa direção a partir de relatórios de surveys com aspectos crescentemente semelhantes.

A análise comparativa entre as diferentes experiências de innovation survey se ampara em estatísticas descritivas relativas à mensuração do desempenho inovador das firmas. A fim de examinar as evidências empíricas de diferentes países se investiga a confiabilidade, a significância e a comparabilidade dos resultados das distintas surveys. Para abordar a qualidade dos dados disponíveis é preciso considerar as especificidades dos países, sejam elas institucionais ou processo de inovação em si, particularmente, dos países em desenvolvimento. Nestes, o foco das surveys, não raro, debruça-se sobre a geração doméstica de conhecimento e de capacitações. Contudo, verifica-se ali uma distância significativa em relação à fronteira tecnológica encontrada nos países desenvolvidos.

Adicionalmente, há duas abordagens principais à coleta de dados sobre inovações TPP (inovação tecnológica de produto e processo) pelas empresas: a "abordagem pelo sujeito", que parte do comportamento inovador e das atividades inovadoras da empresa como um todo, e a "abordagem pelo objeto", que se concentra no número e nas características das inovações individuais. Na primeira versão do Manual de Oslo optou-se por adotar a abordagem pelo sujeito com a expectativa de facilitar uma maior 
padronização internacional. Todavia, o reconhecimento dos pontos fortes da abordagem pelo objeto, para certos tipos de tema, levou à estruturação da versão mais recente deste manual de forma tal que se prestam a ambas as abordagens (OCDE, 2005). Isso pode ser considerado um avanço do ponto de vista do arcabouço metodológico das surveys inspirada no referido manual.

A abordagem pelo objeto se concentra na inovação tecnológica real como o "objeto" de medição. Ela envolve, primeiramente, identificar inovações tecnológicas significativas por meio de pesquisas bibliográficas de publicações técnicas ou científicas. Em comparação com a primeira esta última captura informações qualitativas menos detalhadas sobre as características das inovações. Contudo, muitos indicadores de surveys publicados não são capazes de manifestar a intensidade de inovação entre as firmas. Isso se deve parcialmente à natureza do instrumento de pesquisa, o qual é predominantemente baseado em respostas binárias ou categorias, mas com muitas limitações (O’BRIEN, 2013).

Guellec e Pattison (2001) apontam que os indicadores de taxa de inovação recebem críticas por negligenciar variações na estrutura industrial ao comparar países ou variações nas composições, por porte, das empresas pesquisadas. Os autores apresentam o exemplo de um país com uma parcela maior de firmas inovando apenas uma vez ao longo do período de referência, que parece mais inovador do que um país com uma parcela menor de empresas inovando várias vezes e de forma contínua. Além disso, os indicadores de taxa não revelam nada sobre a qualidade ou a intensidade da inovação que ocorre nas firmas, simplesmente a parcela de empresas que estão inovando.

Depois de discutidas algumas das características e limitações das surveys de inovação já realizadas, pretende-se, na próxima seção, mapear as várias iniciativas dessa natureza realizadas no mundo. Neste espaço também serão apontadas algumas diferenças quanto aos procedimentos metodológicos verificadas entre os países e regiões, o que dificulta a comparação entre eles.

\section{EXPERIÊNCIAS MUNDIAIS DE SURVEYS}

A Europa foi pioneira nas innovation surveys e desenvolveu uma metodologia comum. Até então foram realizadas sete ondas de surveys ('CIS2001', 'CIS2004', 'CIS2006', 'CIS2008', 'CIS2010', 'CIS2012', 'CIS2014'). O modelo europeu de survey foi adotado por países como Rússia e Ucrânia, por exemplo, que apresentaram uma drástica redução das atividades científicas e tecnológicas ao longo dos anos 2000 (BOGLIACINO, 2010).

Godin (2002) recorda que em 1963 foi realizada a primeira survey internacional sobre P\&D. Desde 1992, após a OCDE adotar o Manual de Oslo, foram realizadas algumas rodadas de innovation survey e em 1993 doze países europeus empreenderam a primeira pesquisa dessa natureza, realizada de forma coordenada. Entre eles estão os seguintes países, a saber: Bélgica, Bulgária, Eslováquia, Espanha, Estônia, Grécia, Islândia, Letônia, Lituânia, Portugal, República Tcheca e Romênia (ARUNDEL, 2006). Naquele momento houve um esforço inicial de busca pela proxy ideal da atividade de inovação, bem como de padronização dos indicadores e medidas de inovação.

Conforme aponta BIS (2014), The UK Innovation Survey oferece fotografias periódicas e instantâneas do comportamento inovador das firmas daquele país, além de representar a maior fonte de dados da Comunidade Europeia, os quais são comparáveis entre países e anos distintos, de modo a permitir a constituição de análises de benchmarking do desempenho das empresas. A referida pesquisa trata dos arranjos cooperativos voltados para a inovação, bem como a distribuição setorial e geográfica da inovação.

Fora da Europa uma das regiões que tem realizado o maior esforço relativo à surveys tem sido a América Latina. Após uma primeira geração de pesquisas, os países se moveram na direção de uma padronização que culminou no Manual de Bogotá (2001), o qual corresponde a uma adaptação do Manual de Oslo às peculiaridades regionais (JARAMILLO et al, 2001). No Brasil a Pintec e a Sondagem de Inovação cumprem esse papel. Outras nações da América Latina realizam surveys como se pode verificar no quadro 1. Diversos países asiáticos e africanos também o fazem, como se pode observar no Quadro 2. Na sequência serão discutidos aspectos metodológicos dessas surveys de inovação.

Guillard e Salazar (2017) realizaram uma pesquisa de campo sobre as experiências de surveys em países latino americanos, a partir de uma parceria entre a Rede de Indicadores Científicos e Tecnológicos Iberoamericanos e Interamericanos (RICYT) e o Banco Interamericano de Desenvolvimento (BID). Os 
países incluídos na pesquisa foram aqueles que desenvolveram mais de três rodadas de pesquisas sobre inovação nos últimos anos, entre os quais estão os seguintes países: Argentina, Brasil, Chile, Colômbia, Costa Rica, Equador, México, Panamá, Peru e Uruguai. O objetivo dessa pesquisa de campo foi reunir informações sobre a experiência dos países latino-americanos na realização de pesquisas sobre inovação. Mesmo que os instrumentos de coleta de dados tenham sido inspirados, em sua maioria, num único manual (Manual de Bogotá) encontrou-se uma diversidade considerável nos procedimentos metodológicos. O México é o único país que considera apenas empresas com mais de 20 funcionários como o universo de pesquisa. Argentina, Brasil, Colômbia e Equador têm como população-alvo empresas com pelo menos 10 empregados, enquanto o Uruguai inclui empresas com pelo menos 5 empregados. Ademais, na Colômbia e no Uruguai, são incluídas todas as firmas com faturamento superior a cerca de US\$ 47 mil e a cerca de US\$ 4,25 milhões, respectivamente. Quanto à amostragem, a maioria dos países realiza pesquisas sobre inovação usando amostragem aleatória estratificada, em conformidade com o Manual de Oslo (MO). No caso da Argentina, Chile e Uruguai, a principal atividade econômica da empresa e seu tamanho são usados como variáveis de estratificação. Já no Brasil e no Equador leva-se em conta apenas o tamanho da empresa.

Nese contexto, o Quadro 1 mostra que alguns países pesquisam só o setor industrial, enquanto apenas o Uruguai envolve os setores primário, secundário e terciário. A maioria dos países realizou a primeira pesquisa nos anos 2000 e já conta com três ou mais rodadas de survey já realizadas. Grande parte dos países utilizam o Manual de Bogotá como principal referência metodológica de seu instrumento de pesquisa, bem como apresentam dados contínuos sobre as atividades inovativas.

Quadro 1 - Experiência na realização de pesquisas sobre inovação nos países da América Latina e do Caribe (1995-2016)

\begin{tabular}{|c|c|c|c|c|c|c|c|c|c|}
\hline País & $\begin{array}{l}\text { Instituições } \\
\text { Envolvidas }\end{array}$ & \begin{tabular}{|c} 
Número \\
de \\
Rodadas
\end{tabular} & \begin{tabular}{|l} 
Primeira \\
Pesquisa
\end{tabular} & $\begin{array}{l}\text { Última } \\
\text { Pesquisa }\end{array}$ & $\begin{array}{l}\text { Período de } \\
\text { Observação }\end{array}$ & Setores Cobertos & $\begin{array}{c}\text { Dados } \\
\text { Contínuos }\end{array}$ & $\begin{array}{l}\text { Tamanho } \\
\text { de corte } \\
\text { das firmas }\end{array}$ & \begin{tabular}{|c|} 
Manual e \\
Questionários \\
de referência
\end{tabular} \\
\hline Argentina & $\begin{array}{c}\text { INE \& Mincyt } \text { Mincyt }^{*} \text { y } \\
\text { Ministerio de trabajo }\end{array}$ & 7 & 1997 & $2008-2013$ & $\begin{array}{l}1992-2008 \\
2010-2012\end{array}$ & Indústria & Não & +10 & MB \\
\hline Bolivia & UPB & 1 & 2016 & 2016 & 2013-2015 & Indústria, Serviços e Outros & n.d & n.d & MB/MO, BID \\
\hline Brasil & $\mathrm{IBGE}^{\star}, \mathrm{MCTIC}$ & 6 & 2000 & 2014 & $1998-2014$ & Indústria, Serviços e Outros & Sim & +10 & $\mathrm{MO} / \mathrm{ClS}$ \\
\hline Chile & $\begin{array}{l}\text { INE, Ministerio } \\
\text { de economía* }\end{array}$ & 9 & 1995 & 2013 & $1992-2014$ & Indústria, Serviços e Outros & Sim & +10 & $\mathrm{MO} / \mathrm{CIS}$ \\
\hline Colömbia & DANE & 7 & 1997 & 2015 & $\begin{array}{l}1993-1996 \\
2003-2014 \\
\end{array}$ & Indústria e Serviços & $\begin{array}{l}\text { Sim, } 2003 \\
\text { em diante }\end{array}$ & +20 & $\mathrm{MB} / \mathrm{MO}$ \\
\hline Costa Rica & MICITT* $^{*}$ & 7 & 2008 & 2015 & $2006-2014$ & Indústria e Serviços & Sim & n.d & MO/MB, RICyT \\
\hline Cuba & MCYT & 2 & 2001 & 2006 & $\begin{array}{l}1997-1999 \\
2003-2005\end{array}$ & n.d & Não & n.d & $\mathrm{MO} / \mathrm{MB}$ \\
\hline Ecuador & INEC, Senescyt & 3 & 2001 & 2015 & $\begin{array}{l}1998-2000 \\
2009-2014 \\
\end{array}$ & $\begin{array}{l}\text { Indústria, Mineração } \\
\text { Comércio e Serviços }\end{array}$ & \begin{tabular}{|l|} 
Sim, 2009 \\
em diante
\end{tabular} & n.d & $\begin{array}{l}\mathrm{MO} / \mathrm{ClS}, \\
\text { Ricyt/CIS }\end{array}$ \\
\hline El Salvador & $\begin{array}{c}\text { DICA, } \\
\text { Ministerio de economía } \\
\end{array}$ & 1 & 2013 & 2016 & $2010-2015$ & n.d & $\begin{array}{l}\text { Sim, } 2010 \\
\text { em diante }\end{array}$ & n.d & BID \\
\hline México & INEGI, CONACYT & 5 & 1997 & 2012 & $\begin{array}{l}1994-1996 \\
1999-2000 \\
2004-2012 \\
\end{array}$ & Indústria e Serviços & $\begin{array}{l}\text { Sim, } 2004 \\
\text { em diante }\end{array}$ & +50 & $\mathrm{MO} / \mathrm{CIS}$ \\
\hline Panamá & SENACYT & 3 & 2001 & 2013 & $\begin{array}{l}1996-1999 \\
2006-2010\end{array}$ & Indústria e Serviços & $\begin{array}{c}\mathrm{Si}, 2006 \\
\text { en } \\
\text { adelante }\end{array}$ & n.d & $\mathrm{MB} / \mathrm{BID}$ \\
\hline Paraguai & CONACYT y DGEEC & 3 & 2007 & 2016 & $\begin{array}{l}2004-2006 \\
2011-2015\end{array}$ & n.d. & $\begin{array}{l}\text { Sim, } 2011 \\
\text { em diante }\end{array}$ & n.d & MB/MO, BID \\
\hline Perú & INEI & 4 & 2000 & 2015 & $\begin{array}{l}1997-1999 \\
2002-2004 \\
2009-2014\end{array}$ & Indústria & $\begin{array}{l}\text { Sim, } 2009 \\
\text { em diante }\end{array}$ & n.d & $\mathrm{MB} / \mathrm{BID}$ \\
\hline $\begin{array}{c}\text { República } \\
\text { Dominicana }\end{array}$ & MESCYT & 2 & 2005 & 2010 & $\begin{array}{l}2003-2005 \\
2007-2009 \\
\end{array}$ & Indústria e Serviços & Não & n.d & $\mathrm{MO} / \mathrm{CIS}$ \\
\hline Uruguay & INE, ANII & 5 & 2001 & 2013 & $1998-2012$ & $\begin{array}{c}\text { Indústria, Serviços e } \\
\text { Agricultura }\end{array}$ & Sim & +5 & MB \\
\hline $\begin{array}{c}\text { Trinidad e } \\
\text { Tobago }\end{array}$ & $\begin{array}{c}\text { Economic Development } \\
\text { Board, Ministry of } \\
\text { Planning and } \\
\text { Development }\end{array}$ & 6 & 2006 & 2015 & n.d. & n.d. & Não & n.d & MB \\
\hline Venezuela & OCEI & 3 & 1996 & 2004 & $\begin{array}{l}1994-1996 \\
2004\end{array}$ & n.d. & Não & +5 & $\mathrm{MO} / \mathrm{MB}$ \\
\hline
\end{tabular}

Fonte: Marins et al (2012) e Guillard e Salazar (2017) (Elaboração Própria)

Quanto à tipologia dos obstáculos à inovação, há uma grande diversidade de questões, embora quase todos os países apontem o fator de alto custo ou baixo retorno como possíveis óbices. Apenas a Argentina e o Panamá também questionam se o período de retorno é considerado longo demais. Todos os países usam a tipologia de inovações do MO: produto, processo, organização e marketing. Em relação ao escopo da 
inovação, todas as nações distinguem entre a inovação ao nível da empresa, do mercado interno e do mercado internacional. No entanto, o Chile distingue entre inovação no nível da empresa e do mercado, que inclui o mercado nacional e internacional. O representante do Chile aponta que é extremamente desafiador utilizar os dados da pesquisa de inovação para realizar a avaliação de impacto, pois é muito difícil cruzar com outros dados administrativos, vinculados a políticas públicas de inovação. Essa dificuldade decorre do fato de que os dados são anônimos por razões de confidencialidade e que existem diferenças estatísticas importantes entre os diferentes bancos de dados. O entrevistado do México considera que seria útil ter uma classificação sobre o grau de inovação do produto para avaliar os avanços em inovação em cada país. O respondente do Peru aponta ser importante ter uma definição de inovação harmonizada e globalmente aceita por todos os países da região, uma vez que os desafios de competitividade ocorrem em nível global (GUILLARD e SALAZAR, 2017).

O Quadro 2 mostra que dezessete países asiáticos já realizaram uma pesquisa sobre inovação. No entanto, muitos deles realizaram apenas uma rodada. Nesse contexto, destaca-se na região o número de rodadas já desenvolvidas pela Tailândia, Malásia e, principalmente, Hong Kong. Por razões dos idiomas, há significativa dificuldade em acessar os formulários e relatórios das pesquisas realizadas naquela região, pois muitos países apresentam documentos apenas em sua língua local. Verifica-se uma forte influência do Manual de Oslo e da CIS no desenvolvimento das pesquisas asiáticas. No entanto, muitas vezes, tal influência - mencionada em documentos oficiais - não é encontrada nos procedimentos metodológicos ou nas questões das pesquisas. Há uma significativa heterogeneidade nesses aspectos dos levantamentos asiáticos, a exemplo do período de observação das surveys, que variam de um a cinco anos. O tamanho mínimo das firmas pesquisadas varia entre um trabalhador e vinte pessoas ocupadas na organização. Alguns países fazem esse recorte relativo ao porte com base no faturamento das empresas. As idiossincrasias das surveys asiáticas e africanas implicam em limitação à comparabilidade (MARINS et al, 2012).

Como se pode notar no Quadro 2, doze países da África já realizaram uma pesquisa sobre inovação, dos quais apenas quatro haviam realizado mais de uma rodada. De acordo com as informações apresentadas por Marins et al (2012), todos os levantamentos se baseiam no Manual de Oslo, mas os procedimentos metodológicos se diferem consideravelmente. Algumas nações avaliam apenas as atividades industriais e outros pesquisam a indústria e o setor de serviços. O tamanho mínimo da amostra também varia entre uma faixa que vai de quinhentos a mil empresas. O único elemento que é exatamente igual em todos os países é o período que compreende cada rodada de survey, qual seja: três anos. O porte mínimo das firmas entrevistadas varia de no mínimo uma pessoa ocupada ao mínimo de 26 trabalhadores.

\begin{tabular}{|c|c|c|c|c|c|c|c|c|c|}
\hline País & $\begin{array}{c}\text { Surveys } \\
\text { Realizadas }\end{array}$ & $\begin{array}{c}\text { Surveys } \\
\text { Disponíveis }\end{array}$ & $\begin{array}{c}\text { Base } \\
\text { Metodológica }\end{array}$ & Região & País & $\begin{array}{c}\text { Surveys } \\
\text { Realizadas }\end{array}$ & $\begin{array}{c}\text { Surveys } \\
\text { Disponíveis }\end{array}$ & $\begin{array}{c}\text { Base } \\
\text { Metodológica }\end{array}$ & Região \\
\hline Burquina Faso & 1 & 1 & $\mathrm{MO} / \mathrm{ClS}$ & Africa & Filipinas & 1 & 1 & $\mathrm{MO} / \mathrm{ClS}$ & Ásia \\
\hline Egito & 3 & 2 & $\mathrm{MO} / \mathrm{ClS}$ & Africa & Hong Kong & 10 & 10 & $\mathrm{MO} / \mathrm{ClS}$ & Ásia \\
\hline Etiopía & 1 & 1 & MO & Africa & Índia & 1 & 1 & $\mathrm{MO} / \mathrm{ClS}$ & Ásia \\
\hline Gana & 1 & 1 & $\mathrm{MO} / \mathrm{ClS}$ & Africa & Indonesia & 2 & 1 & $\mathrm{MO} / \mathrm{ClS}$ & Ásia \\
\hline Lesoto & 1 & 1 & $\mathrm{MO} / \mathrm{ClS}$ & Africa & Kazajistán & 1 & 0 & $\mathrm{MO} / \mathrm{ClS}$ & Ásia \\
\hline Moçambique & 1 & 1 & $\mathrm{MO} / \mathrm{ClS}$ & Africa & Kirguistán & 1 & 0 & $\mathrm{MO} / \mathrm{ClS}$ & Ásia \\
\hline Nigéria & 2 & 1 & $\mathrm{MO} / \mathrm{ClS}$ & Africa & Malásia & 5 & 5 & $\mathrm{MO} / \mathrm{ClS}$ & Ásia \\
\hline Africa do Sul & 4 & 4 & $\mathrm{MO} / \mathrm{ClS}$ & Africa & Palestina & 1 & 0 & $\mathrm{MO} / \mathrm{ClS}$ & Ásia \\
\hline Tanzania & 1 & 1 & $\mathrm{MO} / \mathrm{ClS}$ & Africa & RDP Lao & 1 & 0 & $\mathrm{MO} / \mathrm{ClS}$ & Ásia \\
\hline Tunísia & 2 & 2 & $\mathrm{MO} / \mathrm{ClS}$ & Africa & Singapura & 2 & 0 & $\mathrm{MO} / \mathrm{ClS}$ & Ásia \\
\hline Uganda & 1 & 0 & $\mathrm{MO} / \mathrm{ClS}$ & Africa & Sri Lanka & 1 & 1 & $\mathrm{MO} / \mathrm{ClS}$ & Ásia \\
\hline Zambia & 1 & 0 & $\mathrm{MO} / \mathrm{ClS}$ & Africa & Tailândia & 4 & 3 & $\mathrm{MO} / \mathrm{ClS}$ & Ásia \\
\hline Abu Dabi & 1 & 1 & $\mathrm{MO} / \mathrm{ClS}$ & Ásia & Taiwan & N.D. & N.D. & $\mathrm{MO} / \mathrm{ClS}$ & Ásia \\
\hline Azerbanjão & 1 & 0 & N.D. & Ásia & Coréia do Sul & N.D. & N.D. & $\mathrm{MO} / \mathrm{ClS}$ & Ásia \\
\hline China & 1 & 1 & $\mathrm{MO} / \mathrm{ClS}$ & Ásia & & & & & \\
\hline
\end{tabular}

Fonte: Marins et al (2012) (Elaboração Própria)

Na próxima seção serão apresentados os resultados das experiências brasileiras de surveys, quais sejam: Pintec e Sondagem da Inovação. 


\section{ESCOPO E EXPERIÊNCIAS BRASILEIRAS DE SURVEYS}

\subsection{CARACTERIZAÇÃO E INDICADORES DA PINTEC}

As duas principais innovation surveys aplicadas no Brasil (Pintec e Sondagem da Inovação) apresentam algumas diferenças essenciais. Primeiramente, serão discutidas as principais características e resultados da Pintec e na sequência o mesmo procedimento será adotado para a Sondagem da Inovação. A Pintec foi elaborada primeiro, em 2000, para ser divulgada a cada três anos. A apresentação dos seus resultados, todavia, ocorre com uma defasagem de cerca de dois anos. A pesquisa possui caráter compulsório e confidencial, em conformidade com lei $\mathrm{n}^{\circ} 5.534 / 1963$, que trata do uso exclusivo das informações para fins estatísticos e mantém as informações em forma de código. O período de referência das variáveis qualitativas corresponde a três anos, enquanto as informações quantitativas se referem ao último período de referência da pesquisa. Ela abrange o universo de empresas de portes distintos. O objetivo da Pintec é construir indicadores setoriais nacionais e regionais das atividades de inovação das empresas brasileiras, comparáveis com os dados de outros países. A pesquisa busca identificar os fatores que influenciam o comportamento inovador das empresas, as estratégias adotadas, os esforços realizados, bem como os incentivos, os óbices e os resultados da inovação (IBGE, 2012).

Segundo Koeller (2017) embora vários mecanismos tenham sido instituídos para fomentar a cooperação, o Brasil ainda está entre os países com menores indicadores de firmas inovadoras participando de arranjos cooperativos, embora o percentual de firmas que recebeu financiamento público tenha aumentado para esse fim.

De acordo com De Negri et all (2016), a comparação entre os dados da Pintec 2014 (para o período de 2012-2014) com a edição do triênio anterior (mostrados na Tabela 1) apresenta uma estabilidade da taxa de inovação em torno de $36 \%$ da amostra pesquisada. Comportamento semelhante se manifesta nos outros indicadores de inovação da indústria. Já no setor de serviços a queda da taxa de inovação geral foi mais significativa, na medida em que este indicador era de 46,54\% entre 2006 e 2008 e regrediu para $34,82 \%$ no triênio 2012-2014. Houve queda na inovação de processo, mas a maior parte dela se verificou em relação à inovação de produto para o mercado nacional, que saiu de $37,73 \%$ no primeiro triênio citado para $25,46 \%$ no último.

Tabela 1 - Taxa de inovação na economia brasileira entre 2006 e 2014

\begin{tabular}{|l|c|c|c|c|c|c|c|}
\hline $\begin{array}{c}\text { Período de } \\
\text { referência }\end{array}$ & $\begin{array}{c}\text { Taxa de } \\
\text { inovação }\end{array}$ & $\begin{array}{c}\text { Taxa de } \\
\text { inovação de } \\
\text { produto }\end{array}$ & $\begin{array}{c}\text { Taxa de inovação de } \\
\text { produto novo para o } \\
\text { mercado nacional }\end{array}$ & $\begin{array}{c}\text { Taxa de inovação de } \\
\text { produto novo para o } \\
\text { mercado mundial }\end{array}$ & $\begin{array}{c}\text { Taxa de inovação } \\
\text { de processo }\end{array}$ & $\begin{array}{c}\text { Taxa de inovação de } \\
\text { processo novo para o } \\
\text { mercado nacional }\end{array}$ & $\begin{array}{c}\text { Taxa de inovação de } \\
\text { processo novo para o } \\
\text { mercado mundial }\end{array}$ \\
\hline \multicolumn{7}{|c|}{ Indústria (extrativa e de transformação) } \\
\hline $\mathbf{2 0 0 6}-\mathbf{2 0 0 8}$ & $38,11 \%$ & $22,85 \%$ & $4,10 \%$ & $0,27 \%$ & $32,10 \%$ & $2,32 \%$ & $0,08 \%$ \\
\hline $\mathbf{2 0 0 9}-\mathbf{2 0 1 1}$ & $35,56 \%$ & $17,26 \%$ & $3,66 \%$ & $0,41 \%$ & $31,67 \%$ & $2,12 \%$ & $0,21 \%$ \\
\hline $\mathbf{2 0 1 2}-\mathbf{2 0 1 4}$ & $36,44 \%$ & $18,27 \%$ & $3,77 \%$ & $0,42 \%$ & $32,66 \%$ & $2,56 \%$ & $0,26 \%$ \\
\hline \multicolumn{7}{|c|}{ Serviços } \\
\hline $\mathbf{2 0 0 6}-\mathbf{2 0 0 8}$ & $46,54 \%$ & $37,73 \%$ & $9,55 \%$ & $0,50 \%$ & $31,27 \%$ & $3,15 \%$ & $0,29 \%$ \\
\hline $\mathbf{2 0 0 9}-\mathbf{2 0 1 1}$ & $36,82 \%$ & $27,12 \%$ & $8,81 \%$ & $0,50 \%$ & $31,47 \%$ & $5,38 \%$ & $0,15 \%$ \\
\hline $\mathbf{2 0 1 2}-\mathbf{2 0 1 4}$ & $34,82 \%$ & $25,46 \%$ & $9,05 \%$ & $0,85 \%$ & $28,81 \%$ & $3,70 \%$ & $0,26 \%$ \\
\hline
\end{tabular}

Fonte: Pesquisa de Inovação 2008, 2011 e 2014 - IBGE (Elaboração Própria)

De acordo com Miranda e Koeller (2018), no período 2012-2014, quando foram consideradas apenas as empresas que realizaram dispêndios em atividades inovativas, as pequenas empresas perderam espaço para aquelas de porte médio. Em 2009-2011 cerca de 18\% destas realizaram dispêndio internos em P\&D, enquanto, em 2012-2014, 25\% das empresas deste mesmo porte gastaram com P\&D. Entre as grandes, o crescimento foi ainda maior, registrando uma taxa de inovação de $65,7 \%$ no último período, em comparação a 55,9\% no período anterior. Os dados apresentados na Tabela 2 segmentam as firmas industriais por porte e mostram que a maior parte $(91,2 \%)$ das empresas pesquisadas possui de 10 a 99 pessoas ocupadas e correspondem a 88,3\% das inovações de produto ou processo realizado entre 2009 e 2011 . Contudo, a taxa de inovação destas empresas é de apenas $34,4 \%$, enquanto o maior patamar dessa taxa (55,9\%) é das 
empresas com 500 ou mais profissionais (grande porte). Entre 2012 e 2014 a taxa de inovação das pequenas empresas foi semelhante, mas este indicador aumentou entre as grandes organizações e atingiu os $65,7 \%$.

Tabela 2 - Brasil: variáveis selecionadas das empresas das indústrias extrativas e de transformação, segundo as faixas de pessoal ocupado (2009-2011 e 2012-2014) (Em \%)

\begin{tabular}{|c|c|c|c|c|c|c|c|c|c|c|}
\hline & \multicolumn{5}{|c|}{ 2009-2011 } & \multicolumn{5}{|c|}{ 2012-2014 } \\
\hline & \multicolumn{3}{|c|}{ Participação das empresas } & \multirow[b]{2}{*}{$\begin{array}{c}\text { Taxa de } \\
\text { inovação de } \\
\text { produto e/ou } \\
\text { processo }\end{array}$} & \multirow[b]{2}{*}{$\begin{array}{l}\text { Taxa de participação } \\
\text { de empresas que } \\
\text { realizaram dispêndios } \\
\text { em P\&D interno em } \\
\text { relação ao total d e } \\
\text { empresas inovadoras }\end{array}$} & \multicolumn{3}{|c|}{ Participação das empresas } & \multirow[b]{2}{*}{\begin{tabular}{|c|} 
Taxa de \\
inovação de \\
produto \\
e/ou \\
processo
\end{tabular}} & \multirow[b]{2}{*}{$\begin{array}{l}\text { Taxa de participação } \\
\text { de empresas que } \\
\text { realizaram dispêndios } \\
\text { em P\&D interno em } \\
\text { relação ao total d e } \\
\text { empresas inovadoras }\end{array}$} \\
\hline $\begin{array}{c}\text { Faixas de pessoal } \\
\text { ocupado }\end{array}$ & Total & $\begin{array}{c}\text { Que } \\
\text { implementaram } \\
\text { inovação de } \\
\text { produto e/ou } \\
\text { processo }\end{array}$ & $\begin{array}{c}\text { Que realizaram } \\
\text { dispêndios em } \\
\text { atividades } \\
\text { internas de P\&D }\end{array}$ & & & Total & $\begin{array}{c}\text { Que } \\
\text { implementaram } \\
\text { inovação de } \\
\text { produto e/ou } \\
\text { processo }\end{array}$ & \begin{tabular}{|} 
Que realizaram \\
dispêndios em \\
atividades \\
internas de \\
P\&D \\
\end{tabular} & & \\
\hline De 10 a 99 & 91,2 & 88,3 & 70,7 & 34,4 & 11,3 & 91,3 & 87 & 60,9 & 34,7 & 9,6 \\
\hline De 100 a 499 & 7,1 & 9,1 & 18 & 45,5 & 28,1 & 7 & 10 & 24,9 & 52,1 & 34,1 \\
\hline Com 500 e mais & 1,7 & 2,6 & 11,3 & 55,9 & 60,6 & 1,7 & 3 & 14,3 & 65,7 & 65,3 \\
\hline Total & 100 & 100 & 100 & 35,6 & 14,2 & 100 & 100 & 100,0 & 36,4 & 13,8 \\
\hline $\begin{array}{c}\text { Total - número } \\
\text { de empresas }\end{array}$ & 116.632 & 414.70 & 5876 & - & - & 117.976 & 42.987 & 5.914 & - & - \\
\hline
\end{tabular}

Fonte: Pesquisa de Inovação 2011 e 2014 - IBGE (Elaboração Própria)

Com base nos dados da Pintec 2014 é possível inferir que a recessão recente, experimentada pela economia brasileira, pode ser uma das possíveis explicações para a retração de investimentos das pequenas empresas (firmas de 10 a 99 empregados) em atividades inovativas. Os dados (apresentados na próxima seção) da sondagem da inovação (com amostra composta por grandes empresas) corroboram essa constatação, uma vez que os indicadores de inovação sofreram sensível retração nos períodos imediatamente posteriores ao início de crises econômicas no Brasil. Apoiado nos dados da Pintec constatase que nas demais faixas (empresas de médio e grande portes) houve um aumento do número de empresas que realizaram esforços para inovar, em especial as organizações de porte médio. Nestas, as mudanças parecem acompanhadas por uma alteração no perfil ou na estratégia das firmas, com redução da importância dos gastos com aquisição de máquinas e equipamentos e o aumento dos investimentos em P\&D. Ademais, o maior crescimento no percentual de firmas que recebeu incentivo fiscal para P\&D concentrava-se na faixa de médio porte, sendo boa parte destes financiamentos para a compra de máquinas e equipamentos (MIRANDA e KOELLER; 2018).

São exatamente as grandes empresas que conformam a amostra pesquisada pela Sondagem da Inovação. A próxima seção irá apresentar os principais aspectos metodológicos desta survey.

\subsection{CARACTERIZAÇÃO E INDICADORES DA SONDAGEM DE INOVAÇÃO}

A Sondagem de Inovação vem sendo realizada trimestralmente desde 2010. Aplica-se a uma amostra de empresas representativa do universo brasileiro da indústria extrativa e de transformação, envolvendo apenas companhias com mais de 500 empregados. A Sondagem de Inovação pesquisa uma amostra que envolve 304 organizações de uma população de 1485 empresas, estratificadas em cada divisão CNAE, segundo a variável indicadora de presença ou ausência de P\&D; além disso, para cada CNAE, deve haver pelo menos uma empresa com P\&D e uma empresa sem P\&D. De acordo com ABDI (2017), a Sondagem de Inovação, realizada pela referida instituição, segue os padrões internacionais de coleta e tratamento de dados sobre P\&D disponíveis no "Manual de Oslo", possibilitando compatibilidade metodológica com a Pintec do Instituto Brasileiro de Geografia e Estatística (IBGE) e com pesquisas internacionais, tais como o Community Innovation Survey, realizadas em países da União Europeia.

O percentual de empresas industriais que inovaram (em processo ou produto) e possuem mais de 500 empregados variou entre $71,4 \%$, na primeira edição da Sondagem, até 44,1\%, correspondente à última publicação, que apresenta os dados do quarto trimestre de 2017. O número de organizações que inovaram em produto também apresentou uma trajetória declinante ao longo do período, na medida em que registrou $52,4 \%$ da amostra no $1^{\circ}$ trim. de 2010 e regrediu até se estabilizar em torno de $36 \%$ ao longo do ano de 2017. Entre o começo de 2015 e o final de 2017 a proporção das empresas que introduziram um produto novo para a empresa oscilou em torno de uma média de 33\% da amostra (um patamar bem abaixo do registrado no $1^{\circ}$ trim. de 2010, que foi 52,4\%) (ABDI, 2018). 
Como se pode notar na Tabela 3, desde 2012 cerca de $12 \%$ das empresas, em média, agregou um produto novo para o mercado nacional. Já a inovação de produto, em geral, que era de 52,4\% da amostra no $1^{\circ}$ trim. de 2010 , diminuiu até $36,2 \%$ no $4^{\circ}$ trim. de 2017 . A introdução de novo produto para a empresa estava num patamar de $48,5 \%$ no $1^{\circ}$ trim. de 2010 e se reduziu para 33,2\% ao final de 2017. Quanto à inovação de processo para a empresa, que no início da série histórica estava no patamar dos $55,2 \%$, chegou ao $4^{\circ}$ trim. de 2017 marcando 26,2\%. Desde 2014, aproximadamente 9\% introduziu novo processo para o mercado nacional, enquanto no início da série histórica analisada esse indicador era de 24,8\%. Quando se compara o quarto trimestre dos seis anos da pesquisa (adicionados das estatísticas do primeiro semestre e do último semestre até então publicados) verifica-se uma significativa tendência (de longo prazo) de decrescimento da taxa de inovação em todos os indicadores.

Tabela 3: Percentual de empresas industriais com mais de 500 pessoas ocupadas que inovaram $-2010 / 2017$

\begin{tabular}{|l|c|c|c|c|c|c|c|c|c|}
\hline \multicolumn{1}{|c|}{ Percentual de Empresas } & $\begin{array}{c}10 \text { Tri } \\
2010\end{array}$ & $\begin{array}{c}40 \text { Tri } \\
2010\end{array}$ & $\begin{array}{c}40 \text { Tri } \\
2011\end{array}$ & $\begin{array}{c}40 \text { Tri } \\
2012\end{array}$ & $\begin{array}{c}40 \text { Tri } \\
2013\end{array}$ & $\begin{array}{c}40 \text { Tri } \\
2014\end{array}$ & $\begin{array}{c}40 \text { Tri } \\
2015\end{array}$ & $\begin{array}{c}40 \text { Tri } \\
2016\end{array}$ & $\begin{array}{c}40 \text { Tri } \\
2017\end{array}$ \\
\hline $\begin{array}{l}\text { Inovadoras de Produto ou } \\
\text { Processo }\end{array}$ & $71,4 \%$ & $61,6 \%$ & $54,5 \%$ & $51,8 \%$ & $50,2 \%$ & $47,8 \%$ & $44,9 \%$ & $49,5 \%$ & $44,1 \%$ \\
\hline De produto & $52,4 \%$ & $48,4 \%$ & $42,4 \%$ & $38,8 \%$ & $39,3 \%$ & $35,0 \%$ & $34,1 \%$ & $40,9 \%$ & $36,2 \%$ \\
\hline Produto novo para empresa & $48,5 \%$ & $44,6 \%$ & $37,4 \%$ & $35,6 \%$ & $36,0 \%$ & $30,9 \%$ & $32,2 \%$ & $35,9 \%$ & $33,2 \%$ \\
\hline $\begin{array}{l}\text { Produto novo para o mercado } \\
\text { nacional }\end{array}$ & $18,1 \%$ & $18,4 \%$ & $18,3 \%$ & $12,7 \%$ & $13,3 \%$ & $12,6 \%$ & $11,9 \%$ & $14,9 \%$ & $11,9 \%$ \\
\hline De processo & $55,2 \%$ & $45,8 \%$ & $36,4 \%$ & $35,0 \%$ & $37,1 \%$ & $33,3 \%$ & $29,0 \%$ & $30,9 \%$ & $26,2 \%$ \\
\hline Processo novo para a empresa & $48,6 \%$ & $41,5 \%$ & $32,1 \%$ & $31,5 \%$ & $33,3 \%$ & $28,6 \%$ & $25,7 \%$ & $28,5 \%$ & $23,3 \%$ \\
\hline $\begin{array}{l}\text { Processo novo o mercado } \\
\text { nacional }\end{array}$ & $24,8 \%$ & $15,5 \%$ & $11,6 \%$ & $8,6 \%$ & $12,6 \%$ & $9,4 \%$ & $8,7 \%$ & $8,6 \%$ & $9,1 \%$ \\
\hline
\end{tabular}

Fonte: Elaboração Própria a partir de dados da ABDI (vários números)

Ademais, a taxa de inovação esteve sempre abaixo da expectativa de inovação declarada pelas empresas no trimestre imediatamente anterior, conforme fica evidente no Gráfico 1. Em outros termos significa afirmar que as expectativas de inovação não se confirmaram em sua totalidade. Essa diferença entre a intenção de inovar e a taxa de inovação, em particular, se reduziu $4^{\circ}$ trim. de 2016 . A taxa de inovação $4^{\circ}$ trim. de 2017, quando comparada com $2^{\circ}$ trim. de 2010, apresenta uma queda considerável, da ordem de vinte e sete pontos percentuais, ao passar de $71 \%$ para $44 \%$. O cenário de desaquecimento econômico, verificado mais intensamente a partir do ano de 2014, se manifestou no arrefecimento do ímpeto inovador das empresas industriais brasileiras. $\mathrm{O} 1^{\circ}$ trim. de 2016 corresponde ao nível mais baixo da taxa de inovação $(37,6 \%)$ desde o início da pesquisa em 2010. Houve, de forma geral, uma tendência de queda relacionada à concretização das inovações no período de 2010 a 2017. Observa-se nos trimestres de 2017 uma estabilidade em torno de 43\% (ABDI, 2018).

O contexto recessivo recente reflete as incertezas do cenário internacional e doméstico que se ampliaram nos últimos anos. A inovação (a exemplo da adoção de novos processos e dispêndio no desenvolvimento de produtos inovadores) requer um ambiente de negócios e macroeconômico mais favorável e menos incerto. A desaceleração da produção industrial e a queda da formação bruta de capital fixo apontam um cenário pouco favorável para a inovação. Os indicadores de expectativa de inovação estão entre os níveis mais baixos da série histórica, após uma queda sistemática ao longo de dois trimestres de 2014 (ABDI, 2015). Ademais, os custos e riscos associados à busca por novas tecnologias desestimulam esforços de inovação. Constatou-se que as inovações são realizadas quando significam incremento na produtividade ou redução de custos.

Ao longo dos oito anos da sondagem da inovação os fatores que influenciaram a decisão de inovar foram: i) pressões adicionais de custo, ii) busca por maior participação no mercado e, iii) exigência de clientes. No referido período estes indicadores foram considerados de alta relevância para a decisão de investimento em inovação de, aproximadamente, dois terços das empresas entrevistadas. Na prática, a expansão dos dispêndios em máquinas e equipamentos representa o principal fator de geração de inovações de processo. Boa parte da inovação na indústria brasileira é incorporada em bens de capital, ou seja, o investimento em máquinas e equipamentos corresponde ao principal gasto em inovação na indústria 
nacional, uma vez que há uma baixa densidade tecnológica da indústria nacional, em que predominam setores de tecnologia madura (ABDI, 2017).

Gráfico 1: Expectativas de inovação e inovação efetivamente realizada nas empresas industriais com mais de 500 pessoas ocupadas (em \%) - 2010/2017

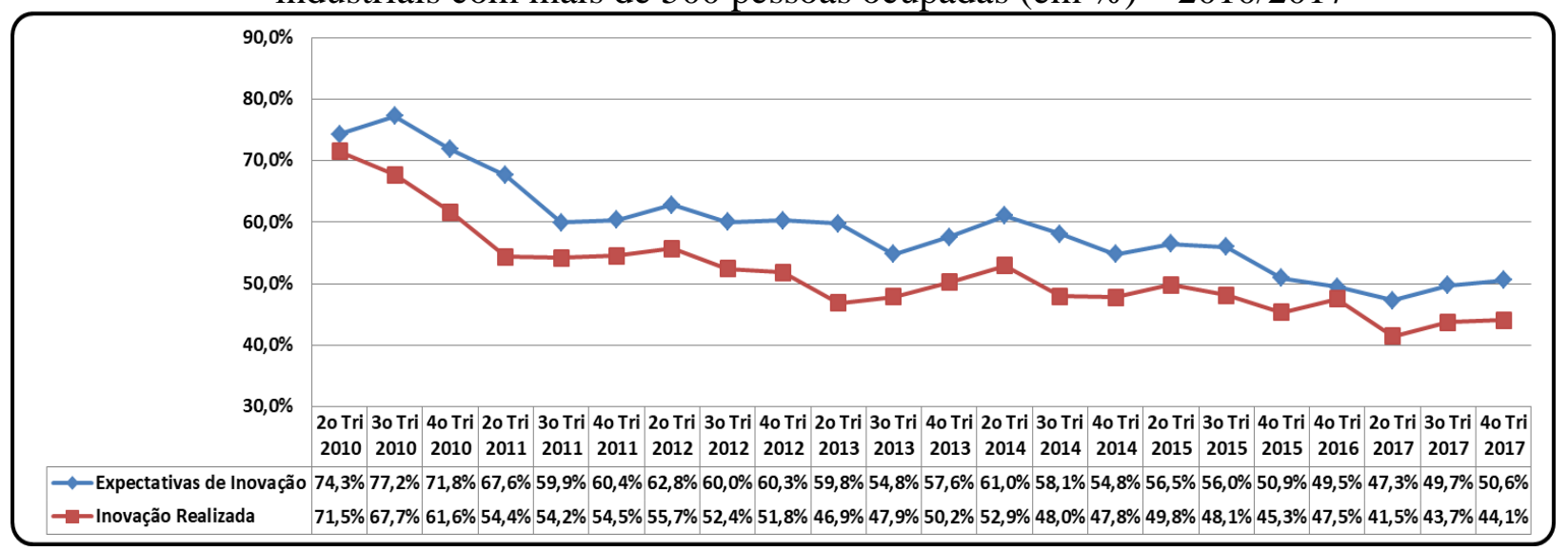

Fonte: Elaboração Própria a partir de dados da ABDI (vários números)

Cabe salientar que a redução da demanda agregada diminui os incentivos para as empresas lançarem novos produtos, ampliarem a capacidade produtiva ou modernizá-la. A indústria brasileira, majoritariamente, introduz produtos e processos já presentes no mercado, o que caracteriza as organizações brasileiras como seguidoras, uma vez que elas inovam de um modo que minimiza os seus riscos e custos. Não raro, essas inovações são importadas de outros mercados, nos quais foram desenvolvidas. Importa salientar que entre as grandes empresas brasileiras predominam organizações de setores com menor intensidade tecnológica, com menores oportunidades e incentivos para inovar, o que explica, em parte, o baixo dinamismo tecnológico da indústria nacional. Conforme fato estilizado, a proporção de firmas que lançaram produtos e processos novos para o mercado nacional é menor do que o percentual de empresas que introduziram produtos e processos novos para a empresa, mas já existentes para o mercado. Esse resultado evidencia que lançar produtos inovadores para o mercado nacional exige maior esforço de inovação, o qual se concentra em poucas empresas. Por essa razão também se trata de um indicador que apresenta menor variabilidade (ABDI, 2017).

Os dispêndios em P\&D interno mantiveram uma certa estabilidade ao longo do tempo, enquanto os dispêndios em $\mathrm{P} \& \mathrm{D}$ externo se reduziram, consideravelmente, com a recessão econômica recente. A explicação para isso é que as empresas buscam manter seus esforços e equipe internos para não perder conhecimento tácito e competências estratégias acumulada ao longo do tempo, inclusive de absorção de conhecimento e tecnologia externas. Dentre as empresas pesquisadas no $4^{\circ}$ trimestre de $2017,57,2 \%$ possuíam departamento de $\mathrm{P} \& \mathrm{D}$ e $42,8 \%$ não possuíam. Vale salientar que o comportamento dos gastos em P\&D interno não se alterou muito ao longo dos anos de pesquisa da Sondagem. Um exercício econométrico, com base em microdados dos últimos três trimestres (de 2017) da sondagem da inovação, mostra que as firmas que possuem departamento dedicado à $\mathrm{P} \& \mathrm{D}$ têm probabilidade $35,1 \%$ maior em inovar do que aquelas que não possuem tal departamento. Os resultados do $4^{\circ}$ trimestre de 2017 corroboram essa afirmação: $51,2 \%$ das empresas que possuem P\&D inovaram em processos ou produtos no período, enquanto entre as que não possuem departamento de $\mathrm{P} \& \mathrm{D}$, apenas $15,9 \%$ inovaram no período. Já o pessoal ocupado em P\&D não se alterou significativamente mesmo diante de um encolhimento da atividade de inovação (ABDI, 2018).

Libânio et al (2014) ressalta a importância do instrumento da Sondagem por produzir indicadores conjunturais que contribuem para o monitoramento dos esforços tecnológicos das empresas no Brasil. Ademais, contemplam como esforço tecnológico inovações incrementais associadas às iniciativas de imitação. Com base nos dados da Sondagem de Inovação, Libânio et al (2016) sugerem que a economia nacional deve ainda que percorrer um longo caminho no tocante ao dinamismo tecnológico de sua indústria. Sugerem estratégias de ação de política industrial e de inovação, a saber: "(i) aperfeiçoamento do Sistema Nacional de Inovação, envolvendo uma maior descentralização das atividades de pesquisa e inovação e 
intensificação das relações entre o setor produtivo e as instituições de pesquisa; (ii) maior diversificação da estrutura produtiva na indústria nacional", uma vez que na indústria brasileira predominam setores maduros e de médio e baixo dinamismo tecnológico.

Em suma, a Sondagem de Inovação vis a vis a Pintec é mais limitada, não obrigatória, mas com maior periodicidade e divulgação mais célere. Contudo, a sua amostra é composta unicamente por grandes empresas. Muito embora a taxa de inovação, baseada na Pintec, tenha se elevado entre a sua primeira edição (Pintec 2000) de 1998-2000 (31,5\%) e a última (Pintec 2016) de 2012-2014 (36,4\%), esse indicador ainda permanece abaixo da taxa obtida pela Sondagem ABDI, que figurou em quase $48 \%$, no quarto trimestre de 2014, analogamente (ABDI, 2015). Já no quarto trimestre de 2010 a taxa de inovação mensurada pela sondagem da inovação foi superior a $66 \%$, enquanto este mesmo indicador fornecido pela Pintec apontava os 31,5\% supramencionados (ABDI, 2011; PINTEC, 2013). O tamanho da firma é importante determinante do comportamento inovativo, por essa razão os resultados da Pintec podem diferenciar-se significativamente daqueles da Sondagem. Esse resultado corrobora o fato estilizado de que grandes empresas tendem a inovar mais do que firmas menores, uma vez que a amostra da Pintec inclui empreendimentos de menor porte. Ademais, inovação parece ter impactos sobre o desempenho das firmas em termos de rentabilidade, produtividade e geração de emprego.

Por fim, cabe lembrar que os dados apontam uma sensível redução dos esforços de inovação entre as organizações inquiridas ao longo do período de realização da sondagem no Brasil. Na próxima seção serão apresentados os esforços no sentido de comparar os dados da Pintec com aqueles coletados em países da Europa.

\section{COMPARAÇÃO ENTRE SURVEYS DO BRASIL E DA EUROPA}

Cerca de duas décadas depois da difusão das pesquisas de inovação ao redor do mundo, cabe avaliar este processo e questionar se as metodologias de pesquisa baseadas no Manual de Oslo são capazes de fornecer informações úteis sobre inovação. Viotti, Baessa e Koeller (2005) compararam a Pintec 2000 com a CIS 3, que envolveu industriais inovadoras em doze países selecionados - Alemanha, Áustria, Bélgica, Dinamarca, Espanha, Finlândia, França, Grécia, Itália, Holanda, Portugal e Suécia. No ano de 2000, o Brasil apresentava uma taxa de inovação de $31 \%$, melhor apenas do que a Grécia (26\%), e bem inferior à Alemanha (60\%), Bélgica (59\%), Holanda (51\%) e Dinamarca (49\%). A participação das pequenas empresas, com 10 a 49 trabalhadores, era maior na Grécia (76\%), Brasil (78\%), Espanha (82\%) e Itália (86\%). Em todos os países as pequenas firmas eram menos inovadoras, de modo que a concentração mais elevada de empresas de maior porte nos demais países influenciava positivamente a taxa de inovação. O esforço para inovar é um exemplo, pois foi significativo no Brasil $(4,4 \%)$, em relação ao faturamento das firmas, patamar este menor apenas que o apresentado pela Alemanha $(5,35)$ e Bélgica $(5,5 \%)$. A diferença é que destes dispêndios os dois países europeus direcionaram $30 \%$ e $28 \%$, respectivamente, para a aquisição de máquinas e equipamentos. O Brasil concentrou $52 \%$ dos gastos nestas aquisições.

Destarte, entre 1998-2000 o Brasil não apresentava um processo de inovação baseado em relações de cooperação. Em termos das relações de cooperação para projetos de $\mathrm{P} \& \mathrm{D}$ e inovação, o Brasil tinha uma proporção pequena (11\%) de empresas inovadoras com arranjos cooperativos com outras empresas ou instituições. Apenas Itália $(8 \%)$ e Espanha (10\%) tinham proporções menores, enquanto os demais apresentavam proporções mais expressivas de cooperação na inovação: França (35\%), Bélgica (24\%) e Alemanha (19\%). O Brasil estava em último lugar no que se refere à porcentagem de empresas inovadoras (11\%) que receberam financiamentos públicos para o desenvolvimento das atividades inovativas, enquanto a média das firmas industriais dos países selecionados foi de $35 \%$. Em suma, o processo de inovação no Brasil era pouco dinâmico, indicando uma estratégia imitadora, baseada em atividades inovativas concentradas na aquisição de máquinas e equipamentos. Também predominavam inovações de processo, novos para as empresas, em relação às inovações de produto, ou inovações consideradas novas para o mercado (VIOTTI, BAESSA e KOELLER, 2005). É preciso lembrar que cada survey apresenta os seus vieses, em decorrência dos diferentes conceitos utilizados pelas pesquisas. No entanto, a diferença é significativa entre os resultados apresentados pelo Brasil e pelos países com posições de liderança nos indicadores de inovação, com raras exceções. 
Segundo Koeller (2018) a taxa de inovação, para o Brasil, das empresas ativas em inovação (que inovaram em produtos e/ou processos), incluindo empresas com projetos incompletos ou abandonados, no período 2012-2014, foi de 39\%, como se pode notar na Tabela 4. Considerando o conjunto dos 32 países da CIS, o Brasil ficou em $15^{\circ}$ lugar. Os seis primeiros países apresentaram taxas de inovação próximas a $50 \%$, enquanto o resultado dos seis últimos países foi igual ou inferir a $20 \%$. O desempenho brasileiro ficou abaixo da média dos quinze países da União Europeia, na medida em que apresentou a mesma taxa de inovação que a Grécia (39\%) e ficou à frente de Dinamarca (38\%), da Itália (37\%) e da Espanha (23\%). Quando se analisa a estrutura produtiva no Brasil por porte, há uma concentração nas firmas de 10 a 49 trabalhadores $(81 \%)$, as quais apresentam taxa de inovação de $36 \%$. O conjunto de empresas aqui tratadas como de porte intermediário (50 a 249 pessoas ocupadas) corresponderam a $15 \%$ da amostra pesquisada e metade delas $(50 \%)$ realizou inovação em produto ou processo. As organizações de maior porte (mais de 250 trabalhadores) representaram apenas 3\% da amostra e é o grupo com maior taxa de inovação (62\%). Esta correlação positiva entre o tamanho das empresas e a taxa de inovação está presente em todos os países, o que muda é a amplitude da diferença entre as três categorias de tamanho. Chama a atenção os três países (Bélgica, Suíça e Alemanha) que apresentam os maiores indicadores gerais de inovação (53\%), uma vez que a taxa de inovação é relativamente alta em todos os portes de organizações, de modo que neles é menor a diferença do desempenho inovativo entre as firmas de menor porte e as empresas de maior porte.

Autant-Bernard et al (2010), baseados na Community Innovation Survey, sugerem o emprego da taxa de adoção das inovações como elemento central na avaliação do desempenho inovador. Apoiados na mesma survey, Hashia e Stojcic (2013) encontram uma relação positiva entre as atividades de inovação e a produtividade e corroboram o fato estilizado de que as grandes são mais propensas à inovação.

Tabela 4 - Empresas inovadoras em produtos e/ou processos (incluindo empresas com projetos incompletos ou abandonados), por porte, e participação das empresas por porte no total da população (2012-2014)

\begin{tabular}{|c|c|c|c|c|c|c|c|}
\hline $\begin{array}{l}\text { País/grupo de } \\
\text { países }\end{array}$ & $\begin{array}{c}\text { Taxa de inovação } \\
\text { das empresas } \\
\text { inovadoras em } \\
\text { produtos e/ou } \\
\text { processos }\end{array}$ & $\begin{array}{c}\text { Participação das } \\
\text { empresas com } 10 \\
\text { a } 49 \text { pessoas } \\
\text { ocupadas no total }\end{array}$ & $\begin{array}{c}\text { Taxa de inovação das } \\
\text { empresas de } 10 \text { a } 49 \\
\text { pessoas ocupadas. } \\
\text { Inovadora em produtos } \\
\text { e/ou processos }\end{array}$ & \begin{tabular}{|c|} 
Participação \\
das empresas \\
com 50 a 249 \\
pessoas \\
ocupadas no \\
total \\
\end{tabular} & $\begin{array}{c}\text { Taxa de inovação das } \\
\text { empresas de } 50 \text { a } 149 \\
\text { pessoas ocupadas. } \\
\text { Inovadora em produtos } \\
\text { e/ou processos }\end{array}$ & \begin{tabular}{|c} 
Participação \\
das empresas \\
com 250 ou \\
mais pessoas \\
ocupadas no \\
total
\end{tabular} & $\begin{array}{l}\text { Taxa de inovação das } \\
\text { empresas de com } 250 \text { ou } \\
\text { mais pessoas ocupadas. } \\
\text { Inovadora em produtos } \\
\text { e/ou processos }\end{array}$ \\
\hline Bélgica & $53 \%$ & $71 \%$ & $48 \%$ & $25 \%$ & $62 \%$ & $4 \%$ & $77 \%$ \\
\hline Suíca & $53 \%$ & $73 \%$ & $48 \%$ & $23 \%$ & $64 \%$ & $4 \%$ & $78 \%$ \\
\hline Alemanha & $53 \%$ & $74 \%$ & $48 \%$ & $21 \%$ & $61 \%$ & $5 \%$ & $83 \%$ \\
\hline Islândia & $50 \%$ & $78 \%$ & $43 \%$ & $16 \%$ & $76 \%$ & $5 \%$ & $80 \%$ \\
\hline Irlanda & $49 \%$ & $79 \%$ & $45 \%$ & $17 \%$ & $61 \%$ & $5 \%$ & $77 \%$ \\
\hline Finlândia & $48 \%$ & $78 \%$ & $45 \%$ & $18 \%$ & $58 \%$ & $4 \%$ & $73 \%$ \\
\hline Holanda & $47 \%$ & $77 \%$ & $42 \%$ & $19 \%$ & $62 \%$ & $4 \%$ & $70 \%$ \\
\hline Noruega & $46 \%$ & $76 \%$ & $43 \%$ & $19 \%$ & $54 \%$ & $4 \%$ & $66 \%$ \\
\hline Portugal & $45 \%$ & $80 \%$ & $41 \%$ & $17 \%$ & $57 \%$ & $2 \%$ & $78 \%$ \\
\hline Áustria & $44 \%$ & $77 \%$ & $38 \%$ & $18 \%$ & $61 \%$ & $5 \%$ & $82 \%$ \\
\hline Suécia & $44 \%$ & $80 \%$ & $41 \%$ & $16 \%$ & $57 \%$ & $3 \%$ & $72 \%$ \\
\hline Luxemburgo & $42 \%$ & $73 \%$ & $38 \%$ & $22 \%$ & $50 \%$ & $5 \%$ & $65 \%$ \\
\hline União Europeia (15) & $42 \%$ & $79 \%$ & $38 \%$ & $17 \%$ & $55 \%$ & $4 \%$ & $73 \%$ \\
\hline Reino Unido & $41 \%$ & $78 \%$ & $39 \%$ & $18 \%$ & $49 \%$ & $4 \%$ & $54 \%$ \\
\hline França & $41 \%$ & $79 \%$ & $36 \%$ & $17 \%$ & $55 \%$ & $4 \%$ & $73 \%$ \\
\hline Brasil & $39 \%$ & $81 \%$ & $36 \%$ & $15 \%$ & $50 \%$ & $3 \%$ & $62 \%$ \\
\hline Grécia & $39 \%$ & $86 \%$ & $37 \%$ & $13 \%$ & $47 \%$ & $2 \%$ & $79 \%$ \\
\hline Turquia & $38 \%$ & $79 \%$ & $36 \%$ & $17 \%$ & $42 \%$ & $4 \%$ & $54 \%$ \\
\hline Dinamarca & $38 \%$ & $74 \%$ & $34 \%$ & $22 \%$ & $45 \%$ & $4 \%$ & $64 \%$ \\
\hline Itália & $37 \%$ & $86 \%$ & $33 \%$ & $12 \%$ & $56 \%$ & $2 \%$ & $76 \%$ \\
\hline Lituânia & $37 \%$ & $78 \%$ & $30 \%$ & $19 \%$ & $55 \%$ & $3 \%$ & $83 \%$ \\
\hline União Europeia & $37 \%$ & $79 \%$ & $33 \%$ & $17 \%$ & $49 \%$ & $4 \%$ & $68 \%$ \\
\hline República Tcheca & $36 \%$ & $75 \%$ & $29 \%$ & $19 \%$ & $54 \%$ & $5 \%$ & $72 \%$ \\
\hline Chipre & $34 \%$ & $83 \%$ & $30 \%$ & $14 \%$ & $48 \%$ & $3 \%$ & $60 \%$ \\
\hline Eslovênia & $33 \%$ & $78 \%$ & $27 \%$ & $18 \%$ & $51 \%$ & $4 \%$ & $77 \%$ \\
\hline Malta & $31 \%$ & $79 \%$ & $26 \%$ & $17 \%$ & $45 \%$ & $3 \%$ & $72 \%$ \\
\hline Croácia & $27 \%$ & $79 \%$ & $24 \%$ & $17 \%$ & $35 \%$ & $4 \%$ & $55 \%$ \\
\hline Espanha & $23 \%$ & $83 \%$ & $19 \%$ & $14 \%$ & $43 \%$ & $3 \%$ & $68 \%$ \\
\hline Estônia & $21 \%$ & $78 \%$ & $16 \%$ & $19 \%$ & $34 \%$ & $3 \%$ & $53 \%$ \\
\hline Eslováquia & $20 \%$ & $74 \%$ & $17 \%$ & $20 \%$ & $26 \%$ & $5 \%$ & $47 \%$ \\
\hline Hungria & $18 \%$ & $78 \%$ & $15 \%$ & $18 \%$ & $26 \%$ & $4 \%$ & $44 \%$ \\
\hline Bulgária & $17 \%$ & $77 \%$ & $13 \%$ & $19 \%$ & $28 \%$ & $4 \%$ & $46 \%$ \\
\hline Polônia & $16 \%$ & $78 \%$ & $11 \%$ & $19 \%$ & $29 \%$ & $4 \%$ & $56 \%$ \\
\hline Letônia & $14 \%$ & $80 \%$ & $10 \%$ & $17 \%$ & $27 \%$ & $3 \%$ & $51 \%$ \\
\hline Romênia & $6 \%$ & $77 \%$ & $6 \%$ & $18 \%$ & $7 \%$ & $4 \%$ & $17 \%$ \\
\hline
\end{tabular}

Fonte: Eurostat e IBGE 
Koeller (2017) comparou o perfil da inovação no Brasil, em 2014, com aquele encontrado nos países da União Europeia. As edições de 2014 da Pintec e da CIS remetem-se ao período 2012-2014, o que permite uma nova comparação de seus resultados. Uma das perguntas norteadoras do trabalho da autora é a seguinte: Será que a dinâmica da inovação no Brasil permanece a mesma que em 2000? Constatou-se que o Brasil tem uma dinâmica de inovação baseada em processos característicos de economias imitadoras e ainda possui um perfil semelhante ao encontrado em 2000. Em termos relativos o Brasil mostrou uma taxa de inovação abaixo da média da União Europeia, com quinze países. As firmas apresentavam baixo dinamismo inovador e uma estrutura ainda concentrada em firmas de menor porte. O perfil do Brasil também era diferente quanto às características das inovações realizadas em relação aos países líderes em taxas de inovação. Enquanto estes concentraram suas inovações em produto ou em produto e processo, no Brasil predominavam inovações em processo.

Quanto ao grau de novidade também há uma grande disparidade entre os demais países e o Brasil, que ocupava a penúltima posição na porcentagem de produtos novos para o mercado. O país também apresentou baixas porcentagens de empresas desenvolvendo atividades de P\&D interno e externo. Foi constatado elevado percentual de empresas que realizaram aquisição de máquinas, equipamentos e software. Já nos seis países líderes verificou-se o contrário, pois a porcentagem de gastos em P\&D interno era superior ao percentual de dispêndios na aquisição de máquinas, equipamentos e software. A comparação dos indicadores da CIS 2014 com os da Pintec 2014 indicam que o processo de geração de inovação no Brasil ainda está subordinado à lógica de um país imitador. As características do processo inovativo sinalizam que a maioria das empresas do país adotava uma estratégia de busca fundada em processos de absorção de tecnologia. Também há indícios de que mesmo com estratégia baseada nesses processos, de forma geral, as firmas não pareciam estar aperfeiçoando a sua capacidade de absorção, uma vez que as atividades de P\&D não eram consideradas necessárias. Por fim, vale salientar que o desafio da comparação está sempre presente, pois os questionários têm idiossincrasias. A partir de 2012, foram realizados esforços importantes para ampliar a harmonização entre países respondentes da CIS 2014, mas ainda haveria espaço para harmonização da Pintec e da CIS (KOELLER, 2017). O perfil da inovação também corresponde ao fato de ela ser nova para o mercado ou apenas para a empresa. O grau de novidade possibilita, em conjunto com outras características, revelar qual é a estratégia das empresas - imitadora, seguidora ou líder em inovação. Os indicadores disponíveis permitem verificar se a inovação realizada, tanto em produto quanto em processo, é nova para a firma ou nova para o mercado, como se pode constatar na Tabela 5.

Tabela 5 - Empresas que inovaram para o mercado em relação ao total das empresas que inovaram, em produtos e processos (2012-2014), em percentual

\begin{tabular}{|c|c|c|c|c|c|c|c|}
\hline $\begin{array}{c}\text { País/grupo de } \\
\text { países }\end{array}$ & $\begin{array}{c}\text { Empresas que } \\
\text { inovaram em } \\
\text { produto para o } \\
\text { mercado em relação } \\
\text { ao total de empresas } \\
\text { que inovaram em } \\
\text { produtos }\end{array}$ & $\begin{array}{c}\text { Empresas que } \\
\text { inovaram em } \\
\text { processo para o } \\
\text { mercado em relação } \\
\text { ao total de empresas } \\
\text { que inovaram em } \\
\text { processos }\end{array}$ & $\begin{array}{c}\text { Empresas que } \\
\text { vendem produtos } \\
\text { e/ou serviços no } \\
\text { mercado nacional }\end{array}$ & $\begin{array}{l}\text { País/grupo de } \\
\text { países }\end{array}$ & $\begin{array}{c}\text { Empresas que } \\
\text { inovaram em } \\
\text { produto para o } \\
\text { mercado em } \\
\text { relação ao total } \\
\text { de empresas que } \\
\text { inovaram em } \\
\text { produtos }\end{array}$ & $\begin{array}{c}\text { Empresas que } \\
\text { inovaram em } \\
\text { processo para o } \\
\text { mercado em } \\
\text { relação ao total } \\
\text { de empresas que } \\
\text { inovaram em } \\
\text { processos } \\
\end{array}$ & $\begin{array}{c}\text { Empresas que } \\
\text { vendem produtos } \\
\text { e/ou serviços no } \\
\text { mercado } \\
\text { nacional }\end{array}$ \\
\hline Islândia & - & 65 & 70 & Polônia & 55 & 28 & 77 \\
\hline Letônia & 75 & 26 & 85 & República Checa & 54 & - & 80 \\
\hline Áustria & 71 & - & 77 & Bulgária & 52 & 26 & 62 \\
\hline Eslovênia & 69 & 28 & 78 & UE (28 países) & 52 & - & - \\
\hline Bélgica & 69 & - & - & UE (15 países) & 52 & - & - \\
\hline França & 67 & 31 & 84 & Espanha & 51 & - & 89 \\
\hline Turquia & 67 & 36 & 56 & Portugal & 51 & 33 & 83 \\
\hline Noruega & 67 & 35 & 76 & Dinamarca & 44 & - & - \\
\hline Chipre & 65 & 37 & 93 & Croácia & 44 & 17 & 72 \\
\hline Luxemburgo & 64 & - & 90 & Lituânia & 43 & 21 & 77 \\
\hline Grécia & 64 & 25 & 75 & Malta & 41 & 24 & 87 \\
\hline Itália & 63 & 30 & 84 & Reino Unido & 40 & - & - \\
\hline Irlanda & 62 & - & 72 & Alemanha & 39 & - & 75 \\
\hline Eslováquia & 60 & 16 & 83 & Romênia & 36 & 18 & 74 \\
\hline Finlândia & 59 & - & 84 & Suíça & 34 & - & - \\
\hline Suécia & 59 & 20 & 82 & Brasil & 23 & 9 & - \\
\hline Hungria & 59 & 21 & 94 & Estônia & 10 & 32 & 74 \\
\hline Holanda & 59 & 19 & - & - & - & - & - \\
\hline
\end{tabular}

Fonte: Eurostat e IBGE 
Dos 29 países analisados o Brasil tem o segundo pior desempenho quanto à inovação de produtos novos para o mercado apenas 23\% das empresas alcançaram esse tipo de inovação. Já os dois países em melhores condições neste quesito foram Letônia (75\%) e Áustria (71\%). Na Tabela 5 verifica-se, ainda, que o Brasil esteve na última posição em relação à porcentagem $(9 \%)$ de firmas que inovaram em processo para o mercado. Cumpre notar que a diferença em relação à Islândia (65\%), líder nesta variável, é muito grande. $\mathrm{Na}$ maioria dos países o indicador de empresas que vendem produtos e/ou serviços no mercado nacional correspondem a mais de $70 \%$ das empresas pesquisadas. Em suma, as inovações do Brasil são muito concentradas em processo, com participações relativamente baixas de inovações somente em produtos, bem como pequenos percentuais de produtos e processos novos para o mercado. Essas condições sugerem que o país inova, em grande medida, com fins de modernização, baseado em imitação tecnológica.

Como se pode notar na Tabela 6, no Brasil, 33,6\% das firmas receberam financiamento público à inovação, o que o coloca na sexta posição no grupo de 29 países. Entre os seis países líderes em taxas de inovação, Finlândia $(34,6 \%)$ e Bélgica $(32,8 \%)$ tiveram porcentagens próximas à de empresas brasileiras inovadoras que acessaram financiamento público para as atividades inovativas. Os dois maiores percentuais foram encontrados na Hungria $(43,4 \%)$ e na Holanda (42,9\%), enquanto a Alemanha $(21,0 \%)$ foi o $23^{\circ}$ país e a Suíça $(12,3 \%)$ o $29^{\circ}$ entre os vinte nove países analisados. Naturalmente, uma maior oferta de crédito privado para a inovação em determinados países pode tornar menos importante a concessão pública de financiamento a essa atividade. Por essa razão países com elevados indicadores de inovação podem figurar entre aqueles nos quais há pouco financiamento público à inovação. Tal situação reduz eventuais associações entre o desempenho inovativo de um país e o percentual de empresas que receberam algum tipo de financiamento público para inovar.

Tabela 6 - Percentual de empresas que receberam algum tipo de financiamento público para empresas inovadoras em produto e/ ou processo, independente de outras inovações, 2014

\begin{tabular}{|c|c|c|c|}
\hline País & $\begin{array}{c}\text { Percentual de empresas } \\
\text { que receberam algum } \\
\text { tipo de financiamento } \\
\text { público }\end{array}$ & $\begin{array}{c}\text { País } \\
\text { Percentual de empresas } \\
\text { que receberam algum } \\
\text { tipo de financiamento } \\
\text { público }\end{array}$ \\
\hline Hungria & $43,4 \%$ & Grécia & $25,5 \%$ \\
\hline Holanda & $42,9 \%$ & Itália & $24,9 \%$ \\
\hline Noruega & $38,3 \%$ & Estônia & $24,1 \%$ \\
\hline Finlândia & $34,6 \%$ & França & $24,0 \%$ \\
\hline República Tcheca & $33,6 \%$ & Luxemburgo & $23,6 \%$ \\
\hline Brasil (1) & $\mathbf{3 3 , 6 \%}$ & Croácia & $23,1 \%$ \\
\hline Bélgica & $32,8 \%$ & Chipre & $21,6 \%$ \\
\hline Espanha & $31,7 \%$ & Alemanha & $21,0 \%$ \\
\hline Bulgária & $30,3 \%$ & Romênia & $20,8 \%$ \\
\hline Turquia & $29,2 \%$ & Malta & $20,1 \%$ \\
\hline Letônia & $28,6 \%$ & Lituânia & $19,4 \%$ \\
\hline Eslovênia & $28,2 \%$ & Suécia & $14,8 \%$ \\
\hline Portugal & $26,9 \%$ & Eslováquia & $13,4 \%$ \\
\hline Reino Unido & $26,8 \%$ & Suíca & $12,3 \%$ \\
\hline Polônia & $26,5 \%$ & - & - \\
\hline
\end{tabular}

Fonte: Eurostat e IBGE.

O Brasil apresentou uma taxa de empresas ativas em inovação relativamente baixa. Diferentemente dos países líderes, os esforços inovativos brasileiros se manifestaram majoritariamente na forma de inovação em processo. O Gráfico 2 mostra que o Brasil era, em 2014, aquele com maior concentração em inovação somente em processo (49\%), seguido da Espanha (43\%) e da Estônia (40\%). Juntamente com a Lituânia, o Brasil apresentava a menor participação de empresas com inovação somente em produto (11\%). Ao contrário disso, a Suíça, o Reino Unido e a Alemanha realizaram cerca de $45 \%$ de inovações de produto e 
aproximadamente $36 \%$ em inovações de produto e processo. Quanto às inovações de produto a faixa de valores mais comuns esteve entre $20 \%$ e $35 \%$. Já nas inovações apenas de processo a maior parte das participações esteve entre $35 \%$ e $50 \%$. A Estônia foi o país com menor participação das inovações em processo (31\%), enquanto a Irlanda esteve no extremo oposto com $56 \%$ neste quesito.

Gráfico 2 - Participação das empresas inovadoras, segundo tipo de inovação - países selecionados (2012-2014) (Em \%)

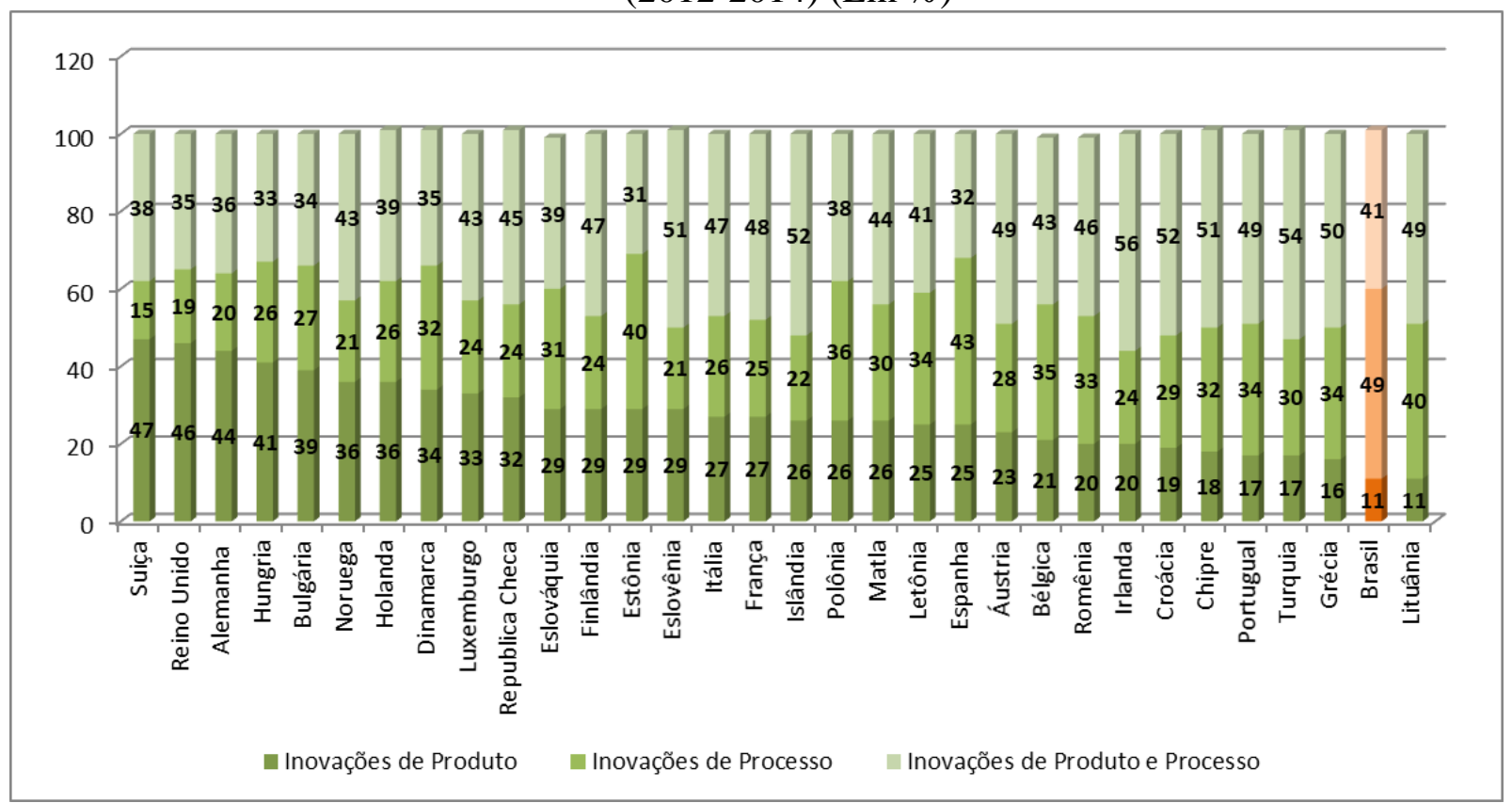

Fonte: Eurostat e IBGE.

Analisando The UK Innovation Survey, Frenz e Ietto-Gillies (2003) sugerem que firmas internacionalizadas são mais propensas a desenvolver atividade de inovação e mantê-las ao longo do tempo. Os autores tampouco encontraram evidências de fortes relações entre a origem das empresas e fa sua propensão à inovação. A respeito desta mesma survey Battisti e Stoneman (2007) encontraram um padrão na atividade inovativa da economia britânica, expresso no fato de que inovações tecnológicas e organizacionais não são substitutas, mas complementares.

Ademais, Hooker e Achur (2014) também analisam a UK Innovation Survey e verificam notáveis melhorias na maioria das atividades de inovação ao longo das últimas pesquisas (entre 2008 e 2012), bem como verificaram que condições macroeconômicas recessivas afetam negativamente as iniciativas inovadoras (assim como se constatou no Brasil e no restante dos países europeus analisados). As taxas aumentaram tanto no indicador de inovações em sentido estrito, quanto em sentido amplo. Já as inovações em produto mudaram pouco, assim como as inovações em processo. Na maioria dos casos os produtos e serviços foram desenvolvidos no interior de uma única firma. Esta constatação vai na direção oposta do que defenderam alguns críticos às surveys de inovação (em suas configurações recentes). Os principais fatores determinantes das inovações foram, em primeiro lugar, o aumento da qualidade dos produtos/processos e, em segundo lugar, a substituição de produtos e processos obsoletos. Os dados do Brasil, quando comparados aos resultados da survey de 2013 do Reino Unido, apontam que é semelhante a taxa de inovação das empresas de menor porte, uma vez que o da Grã-Bretanha figurou em $2013 \mathrm{em} 37 \%$ entre as empresas de 10-250 empregados, assim como na média geral. A diferença é considerável quando comparadas empresas maiores. A taxa de inovação dos europeus em tela é de $39 \%$ entre as empresas com maiores de 250 empregados.

\section{CONSIDERAÇÕES FINAIS}

As innovation surveys permitiram ampliar os conhecimentos sobre inovação e apontam que em grande parte dos países com estrutura industrial estabelecida uma parte considerável das firmas realiza algum tipo 
de inovação. Pode-se considerar ainda incipientes as experiências de muitos países em innovation survey, mas já existem evidências de diversas partes do mundo passíveis de serem comparadas, em alguma medida. Muito embora o Manual de Oslo seja a principal referência conceitual-metodológica para essas pesquisas, ainda não há consenso sobre os melhores indicadores relativos à inovação.

No que tange às experiências de survey do Brasil, a maior frequência da Sondagem de Inovação permite um acompanhamento mais eficiente da trajetória passada e das tendências futuras da atividade de inovação no Brasil. Constata-se, portanto, que a referida pesquisa possibilita uma análise do impacto da conjuntura econômica nos esforços de inovação das empresas, de modo que ela pode ser muito útil como instrumento de gestão para os formuladores de política de inovação. Contudo, a celeridade com que essa pesquisa tem de ser realizada implica em reduzir o seu escopo e, consequentemente, a amplitude dos dados e a profundidade das análises dela derivadas.

A Sondagem de Inovação não contempla um universo de pequenas organizações que operam na fronteira do desenvolvimento tecnológico, a exemplo daquelas relacionadas à nanotecnologia ou demais indústrias transversais, bem como firmas especializadas em determinados nichos de mercado. A diferença entre os instrumentos brasileiros, portanto, está, essencialmente, no fato de que a Sondagem se concentra nas grandes empresas e a atividade de inovação no país é capitaneada pelas grandes corporações. Constatase que a referida pesquisa possibilita uma análise do impacto da conjuntura econômica nos esforços de inovação das empresas, de modo que ela pode ser muito útil como instrumento de gestão para os formuladores de política de inovação.

Ressalta-se, por um lado, que diversos setores estratégicos para o desenvolvimento nacional organizam suas atividades de $\mathrm{P} \& \mathrm{D}$ tecnológico em pequenas unidades fabris. Por outro lado, pesquisas como a Pintec e a CIS têm uma defasagem muito grande e podem dificultar as correções de rumo, em tempo, dos formuladores de política. Contudo, a amplitude do escopo e da amostra destas pesquisas conferem maior representatividade e confiabilidade dos resultados. De fato, as idiossincrasias de certos procedimentos metodológicos e definição da amostra geram desafios relativos à comparabilidade delas.

Divergências metodológicas são encontradas não apenas quando se compara surveys de diferentes regiões e países, mas também entre diferentes rodadas de uma pesquisa no mesmo país (exemplo UK). A ação cooperativa de instituições multilaterais pode contribuir para aprofundar a harmonização das orientações metodológicas dos diversos países que realizam surveys de inovação, embora cada país tem as suas especificidades e necessidades, que não podem ser desconsideradas. Todavia, é preciso haver um grau mínimo de comparabilidade das estatísticas de inovação, uma vez que a utilidade destas está, em grande medida, associada ao cotejo internacional do desempenho inovativo de cada país.

O cotejo intertemporal dos indicadores da Sondagem mostra uma tendência de queda, enquanto os resultados da Pintec estão mais próximos de uma relativa estabilidade em linhas globais. Já a comparação internacional evidencia que a maior parte dos indicadores do Brasil são piores do que aqueles verificados entre os países líderes europeus. Conclui-se que há muito o que se avançar em termos de realização de inovações relevantes no Brasil, bem como no que tange à qualidade e comparabilidade dos instrumentos empregados nas surveys ao redor do mundo, aprimorando a sua aplicabilidade nas políticas públicas dos países.

$\mathrm{Na}$ configuração atual dos complexos industrias, os esforços de inovação envolvem interações e cooperações (entre firmas), em especial entre as que compõem cadeias globais de valor. Neste contexto, a inovação deve ser entendida como uma atividade, mais do que um resultado em si e as surveys devem intensificar os seus mecanismos de identificar esses relacionamentos no bojo de redes complexas de firmas e instituições. Ademais, as surveys devem evitar a categorização binária entre inovadores e não inovadores, de modo a dar ênfase ao grau de inovação realizado pelo indivíduo, o que poderia se manifestar, por exemplo, em categorias de inovadores de baixa, média ou alta intensidades. Isso porquê a taxa de inovação em certo patamar não evidencia qual a importância ou a intensidade das inovações realizadas. Além disso, existe um risco significativo da ocorrência de viés da informação em levantamentos de dados, decorrente da compreensão imprecisa do conceito de inovação por parte dos respondentes, o que requer mecanismos de minimização desse tipo de erro, a exemplo de questões descritivas que sejam complementares a perguntas objetivas, por meio das quais seria possível conferir se o enquadramento da resposta está correto. 
Por fim, dos 29 países analisados o Brasil tem o segundo pior desempenho quanto à inovação de produtos novos para o mercado. Apenas $23 \%$ das empresas alcançaram esse tipo de inovação. Já os dois países em melhores condições neste quesito foram Letônia (75\%) e Áustria (71\%). O Brasil esteve na última posição em relação à porcentagem $(9 \%)$ de firmas que inovaram em processo para o mercado. Cumpre notar que a diferença em relação à Islândia (65\%), líder nesta variável, é muito grande. Em suma, as inovações do Brasil são muito concentradas em processo, com participações relativamente baixas de inovações somente em produtos, bem como pequenos percentuais de produtos e processos novos para o mercado. Essas condições sugerem que o país inova, em grande medida, com fins de modernização, baseado em imitação tecnológica.

\section{BIBLIOGRAFIA}

AGÊNCIA BRASILEIRA DE DESENVOLVIMENTO INDUSTRIAL. Sondagem de Inovação da ABDI. Brasília: ABDI, vários números (disponível em: http://www.abdi.com.br/Paginas/sondagem.aspx) AMARA, Nabil; LANDRY, Rejean. Sources of information as determinants of novelty of innovation in manufacturing firms: evidence from the 1999 statistics Canada innovation survey. Technovation, v. 25, n. 3, p. 245-259, 2005.

ARCHIBUGI, Daniele; PIANTA, Mario. Innovation surveys and patents as technology indicators: the state of the art. In: Innovation, patents and technological strategies, Paris: OECD. 1996.

ARUNDEL, Anthony. Innovation survey indicators: What impact on innovation policy? Science technology and innovation indicators in a changing world: Responding to policy needs. OCDE, p. 4964, 2007.

AUTANT-BERNARD, Corinne et al. Measuring the adoption of innovation. A typology of EU countries based on the Innovation Survey. Innovation - The European Journal of Social Science Research, v. 23, n. 3, p. 199-222, 2010.

BATTISTI, Giuliana.; STONEMAN, Paul. How innovative are UK firms? Evidence from the CIS4 on the synergistic effects of innovations. Report for the Department of Trade and Industry, 2007.

BATTISTI, Giuliana; STONEMAN, Paul. How innovative are UK firms? Evidence from the fourth UK community innovation survey on synergies between technological and organizational innovations. British Journal of Management, v. 21, n. 1, p. 187-206, 2010.

BLANKLEY, William; MOLOTJA, Neo; SCERRI, Mario. Measuring innovation in OECD and nonOECD countries: selected seminar papers. HSRC Press, 2006.

BOGLIACINO, Francesco et al. Innovation and development: The evidence from innovation surveys. Latin American Business Review, v. 13, n. 3, p. 219-261, 2012.

CAVALCANTE, Luiz Ricardo; DE NEGRI, Fernanda. Trajetória recente dos indicadores de inovação no Brasil. Texto para Discussão, Instituto de Pesquisa Econômica Aplicada (IPEA), 2011.

OECD and Eurostat. Oslo Manual: Guidelines for Collecting and Interpreting Innovative Data. 3a Edição, a joint publication of OECD and Eurostat. 2005.

FOWLER JR, Floyd J. Survey research methods. Sage publications, 2013.

FOYN, F. Using the Oslo methodology to measure innovation: The Community Innovation Survey Aproach. IN: BLANKEY, W; SCERRI, M. MOLOTJA, N; SALOOJE (Eds.) OCDE. Measuring innovation in OECD and non-OECD countries. OECD-HSRC Press, Cape Town, p. 111-122, 2006.

FREITAS, Henrique et al. O método de pesquisa survey. Revista de Administração da Universidade de São Paulo, v. 35, n. 3, 2000.

FRENZ, Marion; IETTO-GILLIES, Grazia. The impact on innovation performance of different sources of knowledge: Evidence from the UK Community Innovation Survey. Research Policy, v. 38, n. 7, p. 11251135, 2009.

CASTELLACCI, Fulvio; NATERA, Jose Miguel. Innovation surveys in Latin America: a primer. Innovation and Development, v. 2, n. 1, p. 199-204, 2012.

GODIN, Benoit. A note on the survey as an instrument for measuring science and technology. Project on the History and Sociology of S\&T Statistics, 2002. 
GODIN, Benoit. The rise of innovation surveys: Measuring a fuzzy concept. Canadian Science and Innovation Indicators Consortium, Project on the History and Sociology of S\&T Statistics, Working Paper, v. 16, 2002.

GODIN, Benoit. The linear model of innovation. The historical construction of an analytical framework. Science, Technology, and Human Values, 31 (6): 639-667, 2006.

GODIN, Benoit. The Making of Statistical Standards: The OECD and the Frascati Manual, 19622002. Project on the History and Sociology of STI Statistics, Working Paper, 2008.

GODIN, Benoit. Innovation studies: The invention of a specialty (Part I). Project on the Intellectual History of Innovation, Working Paper, n. 7, 2010.

GUELLEC, Dominique; PATTINSON, Bill. Innovation surveys: Lessons from OECD countries' experience. STI-Science Technology Industry Review, n. 27, p. 77-102, 2000.

GUILLARD, Charlotte; SALAZAR, Mónica. The Experience in Innovation Surveys of Selected Latin American Countries. Inter-American Development Bank, 2017.

DERBYSHIRE, J., HOLLANDERS, H., LEWNEY R., RIVERA LEON, L., TARANTOLA, S. and TIJSSEN R. Regional Innovation Scoreboard 2012 - Methodology report, European Commission, 2012. HOOKER, H.; ACHUR, J. First findings from the UK innovation survey 2013. UK Department for Business Innovation and Skills, London, UK, Tech. Rep, 2014.

IBGE. Instituto Brasileiro de Geografia e Estatística. Pesquisa de Inovação 2011. Rio de Janeiro, 2013 . Instituto Brasileiro de Geografia e Estatística. Pesquisa de Inovação 2014. Rio de Janeiro, 2016

KOELLER, Priscila. Dinâmica da inovação no Brasil em contraposição a países selecionados. IPEA, Rio de Janeiro. 2017.

KOELLER, Priscila. Dinâmica da inovação: Brasil frente aos países da União Europeia (indícios de 2014). IPEA, Rio de Janeiro.2018.

LIBÂNIO, Gilberto; FERREIRA, Cândido; DIAS, Ana; SANTOS, Ulisses; ALENCAR, Douglas; LONDE, Anna. Inovação na indústria de Minas Gerais e do Brasil: uma análise comparativa a partir dos dados da Sondagem de Inovação (2010-2013). In: XVI Seminário de Economia Mineira. Diamantina, 2014.

LIBÂNIO, Gilberto; FERREIRA, Cândido; DIAS, Ana; SANTOS, Ulisses; ALENCAR, Douglas; LONDE, Anna. Inovação na indústria brasileira: uma análise a partir dos dados de um painel de empresas da Sondagem de Inovação. In: XVII Seminário de Economia Mineira, Diamantina, 2016.

LUCKING, Ben. International comparisons of the third community innovation survey (CIS3). DTI, London. 2004.

LUGONES, Gustavo. The Bogota Manual: Standardising innovation. In: Measuring Innovation in OECD and Non-OECD Countries: Selected Seminar Papers. HSRC Press, 2006. p. 163.

JARAMILLO, H.; LUGONES, G.; SALAZAR, M. Bogotá Manual-Standardization of indicators of technological innovation in Latin America and Caribbean Countries. Bogotá: RICYT, OAS, CYTED Program, Colciencias, OCYT, 2001.

MARINS, L., ANLLÓ, G. y SCHAAPER, M. "Estadísticas de innovación: el desafío de la comparabilidad", IN: ALBORNOZ, M (ed.) El estado de la ciencia: principales indicadores de ciencia y tecnología iberoamericanos / interamericanos 2012, Buenos Aires, Red de Indicadores de Ciencia y Tecnología-Iberoamericana e Interamericana, pp. 65-79, 2012.

MIRANDA, Pedro; KOELLER, Priscila. A Inovação e as MPES: uma breve análise do período recente. IPEA, Rio de Janeiro. 2018.

O'BRIEN, K. R. The evolution of subject approaches to innovation measurement, and implications for new innovation indicators. Tese de Doutorado. University of Tasmania. 2013.

OCDE. Innovative networks: co-operation in national innovation systems. Paris: $O C D E$ Publications, 2001.

MANUAL FRASCATI. Proposed Standard Practice for surveys on research and experimental development. OCDE. França. 2002.

QUADROS, Ruy et al. Technological innovation in Brazilian industry: an assessment based on the São Paulo innovation survey. Technological forecasting and social change, v. 67, n. 2-3, p. 203-219, 2001. 
ROMEIRO, Maria do Carmo et al. Pesquisa sobre Inovação Tecnológica: o possível viés da informação em levantamentos. Revista Brasileira de Inovação, v. 13, n. 1, p. 133-162, 2014.

SALAZAR, Mónica; HOLBROOK, Adam. A debate on innovation surveys. Science and public policy, v. 31, n. 4, p. 254-266, 2004.

SMITH, K. Measuring Innovation. In: FAGERBERG, Jan; MOWERY, David C.; NELSON, R. R. The Oxford handbook of innovation. University Press, Oxford, pp. 148-179, 2005.

STEP ECONOMICS. The analysis of CIS II data: towards an identification of regional innovation systems, : Final Report, STEP Economics, Turin. 2000.

STEWARD, Fred; WANG, Y.; TSOI, J. Direct measurement of innovation output using documentary and digital sources. Report for measuring eco-innovation project. European Commission and European Environment Agency, Bruselas, 2008.

TETHER, B.S., 2001. Identifying innovation, innovators and innovative behaviours: A critical assessment of the Community Innovation Survey (CIS). CRIC Discussion Paper No. 48. Manchester: University of Manchester, Centre for Research on Innovation and Competition, 2001.

TOMLINSON, Mark et al. Innovation surveys: A researcher's perspective. Department of Industrial Economics and Strategy, Copenhagen Business School, 2000.

TSAI, Kuen-Hung; WANG, Jiann-Chyuan. External technology sourcing and innovation performance in LMT sectors: An analysis based on the Taiwanese Technological Innovation Survey. Research Policy, v. 38, n. 3, p. 518-526, 2009.

VAUS, DA de. Surveys in social research. New South Wales: Allen and Unwin, 2002.

VIOTTI, Eduardo B.; BAESSA, Adriano Ricardo; KOELLER, Priscila. Perfil da inovação na indústria brasileira: uma comparação internacional. In: DE NEGRI, J. A.; SALERNO, M. (Orgs.). Inovações, padrões tecnológicos e desempenho das firmas industriais brasileiras. Brasília: IPEA, p. 653-687, 2005 